\title{
Chile: ¿Es eficaz la patente por no uso de derechos de aguas?
}

\author{
Christian Valenzuela, Rodrigo Fuster y Alejandro León
}

En este trabajo se examina si la patente por no uso de derechos de aprovechamiento de aguas implementada en Chile en 2005 ha incentivado la utilización de las aguas sin uso. Se analizan descriptivamente dos comparaciones: patentes cobradas respecto de recaudadas y precio de mercado de derechos comparado con el cobro de patente. Se observa que en los sucesivos procesos de cobro de patentes, la recaudación aumentó del $67 \%$ en 2007 al $81,4 \%$ en 2009 respecto del total cobrado. Además, se determinó que varios años de pago de patente equivalen al precio de mercado de los derechos de aguas. Se concluye que la patente no ha sido eficaz en desincentivar el no uso, puesto que los propietarios tienden a pagar lo cobrado para no perder derechos cuyos precios de mercado superan a los de las patentes. Asimismo, se sugieren algunas mejoras al diseño legal del instrumento.

PALABRAS CLAVE

CLASIFICACIÓN JEL

AUTORES
Agua, patentes, derechos sobre las aguas, ordenamiento de las aguas, precios, ingresos, aspectos jurídicos, Chile

Q25, Q28 y H21

Christian Valenzuela es investigador del Laboratorio de Análisis Territorial (LAT) de la Universidad de Chile.cvalenzuela@renare.uchile.cl

Rodrigo Fuster es profesor del Departamento de Ciencias Ambientales y Recursos Naturales Renovables (DCA \& RNR) de la Universidad de Chile.rfuster@uchile.cl

Alejandro León es profesor del Departamento de Ciencias Ambientales y Recursos Naturales Renovables (DCA \& RNR) de la Universidad de Chile. aleon@renare.uchile.cl 


\section{I}

\section{Introducción}

El Código de Aguas que se promulgara en Chile en 1981 permitió que el Estado otorgara a los privados derechos de aprovechamiento de aguas (DAA) gratuitos ${ }^{1} \mathrm{y}$ a perpetuidad, sin que hubiese necesidad de justificar el caudal solicitado, sin informar el rubro productivo relacionado y sin obligación de utilizarlos, lo que generó que una proporción significativa de estos derechos se encontrasen en desuso, impidiendo - una vez agotada legalmente la fuente de agua para constituir nuevos DAA- que proyectos de uso efectivo accediesen a ellos. En 2005 se reformó el Código introduciendo el cobro de una patente por no uso (PNU), a fin de desincentivar la acumulación de derechos por parte de algunos agentes del mercado ${ }^{2}$. En 2011, y luego de cuatro procesos de cobro de la PNU ejecutados y un quinto en ejecución, el propósito de este estudio es determinar si la patente ha desincentivado de manera eficaz la posesión de derechos sin uso efectivo, analizando los resultados de su aplicación.

En la experiencia internacional, los derechos de uso de agua son condicionados a usos específicos, pues al entregar los derechos para usos efectivos y beneficiosos se previene la creación de monopolios y la especulación, como lo indica, por ejemplo, el derecho estadounidense (CEPAL, 1995). Esto no se previó en la legislación chilena, dado que el "no condicionar los derechos a usos efectivos y beneficiosos o adoptar medidas alternativas, ha fomentado la especulación y el acaparamiento, facilitando el manejo de los derechos de agua como un instrumento de competencia económica desleal, y permitido su uso para ejercer un poder de mercado" (Dourojeanni y Jouravlev, 1999). En el derecho comparado, el cobro de una patente de derechos de agua, tal como se aplica en la actualidad en Chile, es peculiar por cuanto supone un enfoque radicalmente distinto al "cobro por uso (o tenencia) del agua" que predomina en países desarrollados (Barde y Braathen, 2002) y en desarrollo (Jouravlev, 2000) cuando existen cobros. De esta forma, la PNU chilena es una excepción

\footnotetext{
${ }^{1}$ La excepción es el remate que lleva a cabo la autoridad estatal en situaciones donde dos o más solicitudes no quedan satisfechas con el agua disponible para constituir nuevos DAA, situación en que sí se paga. ${ }^{2}$ Los derechos entregados antes de 1981 estaban — supuestamenteen uso, puesto que la merced de agua, como se denominaba al DAA con anterioridad a este año, pasaba a ser una merced definitiva solo cuando estaban constituidas las obras de captación (Peña, 2003).
}

a la regla de cobros vinculados a aguas continentales naturales (no potables ni tratadas), lo que la constituye en un interesante elemento de análisis.

Si bien usualmente los especuladores apuestan a obtener una ganancia bajo condiciones de incertidumbre, la situación era diferente en los mercados de agua en Chile, dado que tener un DAA sin uso efectivo no revestía riesgo alguno porque:

i) hasta el año 2006 no se obligaba a los propietarios a invertir en obras 3 para utilizar efectivamente sus derechos;

ii) buena parte de los DAA objeto de especulación fueron otorgados gratuitamente por el Estado; y

iii) aunque se especulara con derechos comprados en el mercado, el riesgo seguía siendo cercano a cero, ya que se ha observado un crecimiento constante de la demanda y los precios de los DAA han registrado una tendencia sostenida al alza (Dourojeanni y Jouravlev, 1999).

Estos argumentos hicieron que el costo de oportunidad resultante de mantener los derechos sin utilizar o sin vender fuera inferior a la rentabilidad derivada del aumento de los precios (Dourojeanni y Jouravlev, 1999), lo que redundó en una situación estratégicamente poco conveniente para el país, considerando que el agua es un recurso natural vital y un insumo productivo sin sustituto.

En consecuencia, en 1992 el Gobierno de Chile definió como modificación central al Código de Aguas la obligación de devolver los DAA no utilizados de manera que caducasen después de un período sin uso (Aylwin, 1992). Sin embargo, esta modificación, que suponía la aplicación de un instrumento del tipo mandato y control, no concitó consenso entre los usuarios y el Parlamento; incluso "hubo un importante debate en el interior del Gobierno" (Lagos, citado por Comisión Especial sobre Régimen Jurídico de las Aguas, 1997). Esto condujo a

\footnotetext{
${ }^{3}$ Estas obras corresponden a captación en el caso de DAA consuntivos y captación y restitución en el caso de DAA no consuntivos. En la legislación chilena de aguas se distingue entre DAA consuntivos y no consuntivos. Los primeros se definen como aquellos que facultan a su propietario para consumir totalmente las aguas en cualquier actividad; mientras que los segundos se definen como aquellos que permiten emplear el agua sin consumirla y obligan a restituirla en la forma que lo determine el acto de adquisición o de constitución del derecho (Ministerio de Justicia, 1981).
} 
que se implementara la noción del cobro por los derechos que no se utilizan (Comisión Especial sobre Régimen Jurídico de las Aguas, 1997), un instrumento económico cuya aplicación logró consensuarse solo después de 13 años de discusión parlamentaria.

El diagnóstico del Ejecutivo indicaba que había alrededor de 50.000 metros cúbicos por segundo $\left(\mathrm{m}^{3} / \mathrm{s}\right)$ en solicitudes al Estado por DAA no consuntivos - realizadas por compañías hidroeléctricas- que estaban pendientes de ser otorgados y que de otorgarse impedirían la constitución de derechos para un conjunto de otros usos y, en consecuencia, frenarían el desarrollo económico. En 1996, la Dirección General de Aguas (DGA) del Ministerio de Obras Públicas (MOP) estimó que los recursos hidroeléctricos (DAA no consuntivos) efectivamente utilizables del país (de la Región de Aysén al norte) alcanzaban como máximo un caudal del orden de $30.000 \mathrm{~m}^{3} / \mathrm{s}$. A esa fecha, los derechos no consuntivos en ejercicio totalizaban un caudal de $1.699 \mathrm{~m}^{3} / \mathrm{s}$ (5,7\% del total estimado efectivamente utilizable), mientras que los constituidos sin uso llegaban a los $11.203 \mathrm{~m}^{3} / \mathrm{s}(37,3 \%)$, y aquellos solicitados y en trámite sumaban $38.509 \mathrm{~m} / \mathrm{s}$ (128\%), mayoritariamente en manos solo de una compañía hidroeléctrica (Comisión Especial sobre Régimen Jurídico de las Aguas, 1997). Las posibilidades de monopolización, de control de la generación hidroeléctrica y de cierre de cuencas para otros usos eran claras (Comisión Preventiva Central, 1996). En ese entonces, la Comisión Preventiva Central (1996) recomendó a la DGA abstenerse de aprobar nuevos derechos no consuntivos mientras no entrara en vigencia una modificación legal con el propósito de asegurar un adecuado uso de las aguas, a menos que se tratase de proyectos de interés general.

De este modo, el cobro se definió como una patente anual a beneficio fiscal a la que quedan afectos, en la proporción no utilizada de sus respectivos caudales, los derechos cuyos propietarios no hubiesen construido las obras necesarias. De no pagarse la patente, el DAA avanza a una instancia de remate. Se estableció que los dineros recaudados por patentes (ya sea de pagos o de remates por no pago) se repartieran entre el Fondo Nacional de
Desarrollo Regional del gobierno regional respectivo (65\%), los municipios en proporción a la superficie de las comunas que intersectan con la cuenca y la zona de inscripción respectiva (10\%), y los fondos fiscales generales del gobierno central (25\%).

Por otra parte, en la reforma se incorporaron diversas situaciones excepcionales en que los derechos se eximen del pago de PNU aun sin existencia de obras ${ }^{4}$, situaciones que se incluyeron para "tranquilizar" a quienes veían amenazas en la reforma (Peña, 2009). Además, la Ley estableció que, una vez construidas las obras necesarias, se le devolviera al propietario - por la vía de la deducción de impuestos_- hasta los últimos seis pagos de PNU en el caso de derechos consuntivos y hasta ocho en el de no consuntivos (MOP, 2005).

De esta forma, los objetivos para establecer el cobro de PNU sobre los DAA fueron (Riestra, 2009a):

i) cautelar la disponibilidad del agua para quienes la necesiten y tengan proyectos, favorecer su uso racional, y eliminar el acaparamiento y la especulación de manera de favorecer la competencia;

ii) constituir DAA por caudales que efectivamente sean utilizados, y

iii) redistribuir los derechos que no se estén utilizando. Dados los propósitos de la PNU detallados anteriormente, la recaudación óptima esperada es nula (Pérez, citado en Comisión de Hacienda del Senado, 2004), situación en la que todos los propietarios estarían utilizando sus derechos de agua.

Luego de esta Introducción, el presente trabajo se organiza de la siguiente manera: la sección II contiene la metodología y los datos recabados en relación con la investigación, en la sección III se entregan los resultados empíricos y la discusión sobre estos, y en la sección IV se ofrecen las conclusiones.

\footnotetext{
${ }^{4}$ Estas situaciones excepcionales se encuentran en los artículos 129 bis 4 numeral 4; 129 bis 5 párrafo quinto; 129 bis 6 párrafos segundo, tercero y cuarto; y 129 bis 9 de la Ley No 20.017 (MOP, 2005).
} 


\section{II}

\section{Metodología y datos}

Un mecanismo para medir la eficacia de la PNU es comparar lo cobrado con lo recaudado. Mientras más cercana a cero sea la recaudación, más éxito estará teniendo esta patente, debido a que aquellos DAA con patentes impagas son rematados por el Estado y adquiridos por nuevos propietarios. Por otra parte, mientras más cercana sea la recaudación a lo cobrado, menos éxito estará teniendo la PNU, ya que pagar patente permite mantener derechos sin uso efectivo.

Otro mecanismo para medir la eficacia de la patente es contrastar el precio de mercado de los derechos en relación con lo cobrado por la PNU, puesto que un mero especulador, propietario de un DAA, podría escoger la opción más rentable (o menos costosa): usar o vender su DAA, o pagar la patente a la espera de transferir su derecho al mejor precio posible.

Atendiendo a lo anterior, y para determinar la eficacia que ha tenido la PNU en su propósito de desincentivar la posesión de derechos sin uso efectivo, se realizó un análisis descriptivo por medio de dos comparaciones.

\section{Patentes cobradas en comparación con las recaudadas}

Esta primera comparación se realizó para los procesos de cobro de 2007 (primer año de cobro de la PNU) a $2009^{5}$, a escala regional y macrozonal para todo el territorio chileno, distinguiendo entre DAA consuntivos y no consuntivos. Se establecieron tres macrozonas, coincidentes con la diferenciación territorial de cobro que tiene la PNU para derechos consuntivos ${ }^{6}$ (véase el gráfico 1). A las patentes también se vinculó la cantidad de derechos y el caudal correspondiente. Se empleó el listado oficial de DAA afectos a pago de PNU y bases de datos que indican la recaudación ${ }^{7}$ en patentes de los

\footnotetext{
5 En el momento de realizarse este estudio, el proceso de cobro de PNU correspondiente a 2010 estaba en curso, mientras que el proceso de 2011 aún no se iniciaba, razón por la que ambos procesos no se incluyeron en esta primera parte del análisis.

${ }^{6}$ A pesar de que la diferenciación territorial de cobro que tiene la PNU para los derechos no consuntivos es distinta, los datos se tabularon para ambos tipos de derechos con la diferenciación descrita con el objetivo de facilitar las comparaciones.

${ }^{7}$ En el listado se encuentran pagos parciales de patentes en casos muy puntuales, los que constituyen un porcentaje cercano a cero respecto del total de patentes recaudadas. Para efectos del análisis solo se consideró
}

derechos listados (DGA, 2010a). Complementariamente, se utilizó el proceso de cobro de 2010 para analizar la salida o permanencia en el listado de los derechos afectos a las 30 patentes más caras, tanto para DAA consuntivos como no consuntivos, suponiendo que para este grupo de derechos existe un mayor incentivo para que comiencen a ser utilizados.

Luego se determinó la eficacia de la PNU mediante los siguientes criterios:

i) "Porcentaje de pago con respecto a patentes cobradas, cantidad de derechos afectos y caudal afecto" (criterio A). Este porcentaje es inversamente proporcional a la posibilidad de que los derechos se redistribuyan, pues mientras se acerca al 100\% indica mayor preferencia de los propietarios por pagar la PNU y mantener derechos en desuso en lugar de utilizar, vender o esperar el remate estatal.

ii) "Diferencias en patentes cobradas, cantidad de derechos afectos y caudal afecto entre procesos de cobro sucesivos" (criterio B). Es decir, si en un año cualquiera el listado contuviese menor cantidad de derechos afectos $-\mathrm{o}$ menor número de patentes cobradas o caudal afecto- con respecto al año anterior, ello significa que hubo salidas de DAA del listado de cobro, lo que implica que se comenzaron a utilizar, cumpliéndose el objetivo de la PNU. La situación inversa, es decir, si en un año cualquiera el listado contuviese mayor cantidad de derechos $-\mathrm{O}$ más patentes cobradas o caudal afecto- respecto del año anterior, ello se deberá a la incorporación de nuevos derechos al proceso de fiscalización, y no necesariamente a que no hubo salidas de derechos del listado. Por lo tanto, al observar esta situación no se podrían obtener conclusiones precisas.

\section{Precio de mercado de derechos respecto del cobro de la patente}

La segunda comparación se realizó de manera diferenciada para DAA consuntivos y no consuntivos. Respecto de los primeros, se comparó a escala regional para todo el territorio chileno, mientras que en relación con los

la recaudación de las patentes que fueron completamente pagadas, dado que las parcialmente pagadas debieran ir a remate por no pago. 
GRÁFICO 1

\section{Regiones de Chile y macrozonas de aplicación de la PNU a los derechos} de aprovechamiento de aguas consuntivos

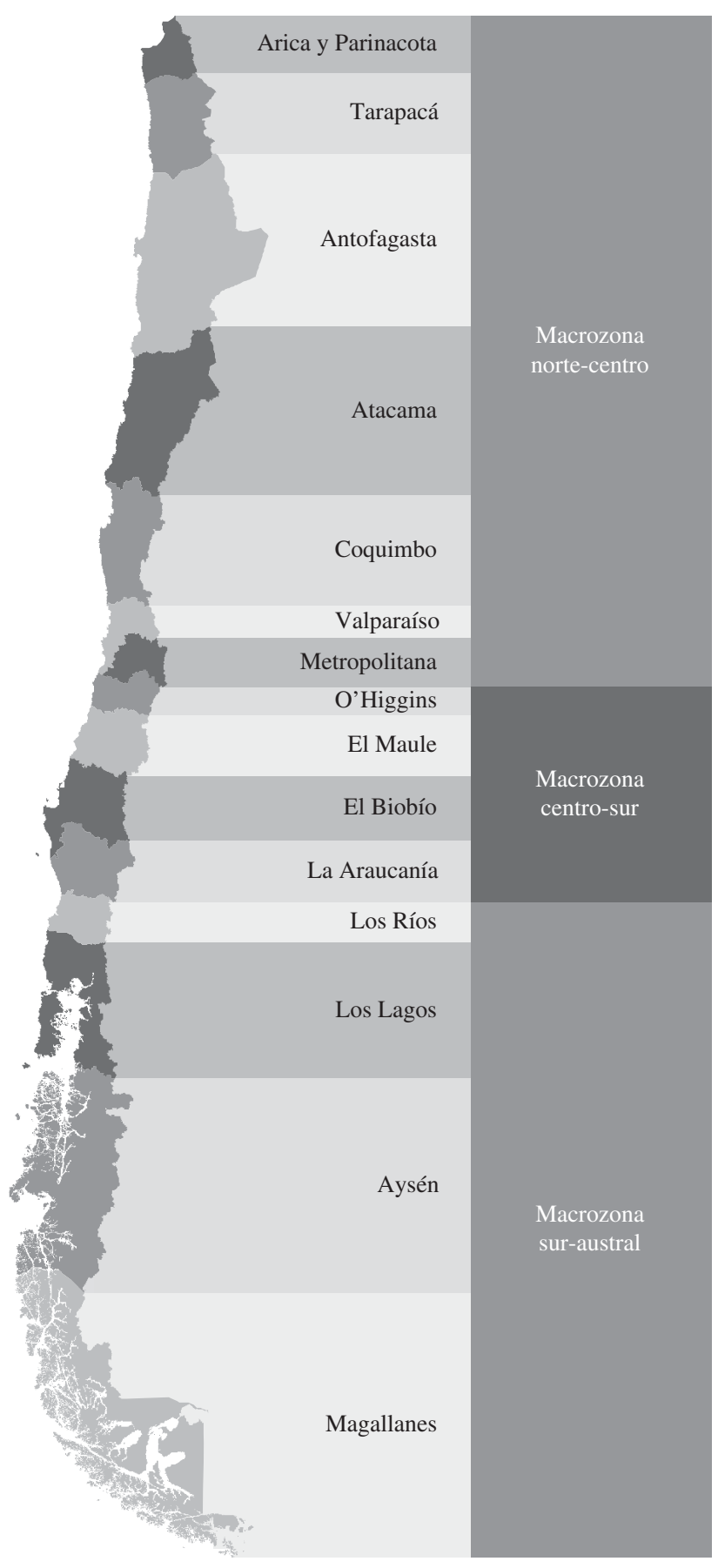

Fuente: elaboración propia.

PNU: patente por no uso. 
segundos la comparación se realizó caso a caso debido a la escasa disponibilidad de datos.

Solo se consideraron transacciones desde 2005 —cuando la PNU entró en vigencia— - hasta 2009, límite de la información disponible para este estudio. Los datos de transacciones se obtuvieron de los registros de los conservadores de bienes raíces (DGA, 2009), la sección de remates de la página web de la DGA (DGA, 2010b) y de la oficina privada "Remates Fernando Zañartu Rozas y Cía. Ltda.” (Gallo, 2010).

Para los derechos consuntivos se estimaron precios promedio de mercado regionales por 50 litros por segundo (1/s) de ejercicio permanente y continuo ${ }^{8}$. La estimación se hizo a escala regional debido a que el grueso de los datos, obtenidos desde la DGA (2009), no permitía confeccionar un listado a nivel de cuencas o acuíferos, unidades geográficas en que se desarrollan los mercados de aguas 9 .

En el caso de los derechos no consuntivos se emplearon todos los registros de transacciones de mercado disponibles que contasen con datos suficientes para calcular la patente ${ }^{10}$ y comparar caso a caso. Este proceder se justifica debido a que las transacciones de DAA no consuntivos:

i) son una fracción menor comparada con las transacciones de DAA consuntivos y existe poco acceso a los datos vinculados a ellas;

ii) están concentradas entre las regiones del Maule y de Los Lagos;

iii) no se pueden promediar, ya que incluyen la variable desnivel entre los puntos de captación y restitución, la que juega un papel importante en el precio al estar relacionada con la potencia hidroeléctrica; y

iv) alcanzan precios que, a diferencia de las transacciones de DAA consuntivos, están menos influenciados por la variabilidad latitudinal y climática (consecuencia de la distribución territorial de Chile), importando más bien variables de tipo local para la valoración de cada litro por segundo, como la cercanía al sistema

\footnotetext{
${ }^{8}$ Además de clasificarse en consuntivos y no consuntivos, los derechos de aprovechamiento de aguas (DAA) son de ejercicio permanente o eventual; y continuo, discontinuo o alternado entre varias personas. El detalle de esta tipología puede consultarse en los artículos 16 a 19 del D.F.L. 1.122 que fija el texto del Código de Aguas (Ministerio de Justicia, 1981).

${ }^{9}$ En Chile las regiones político-administrativas no siempre tienen límites coincidentes con cuencas y nunca con acuíferos.

${ }^{10}$ En la mayoría de los escasos registros disponibles de transacciones de derechos no consuntivos se obvian el desnivel entre los puntos de captación y restitución de las aguas, o bien las coordenadas geográficas de dichos puntos que permitan conocer la altitud y estimar el desnivel, dato necesario para calcular la patente.
}

de distribución de la energía o las condiciones geológicas del cauce, que condicionan el tipo de instalación hidroeléctrica ${ }^{11}$.

Por otra parte, se utilizó la Ley $\mathrm{N}^{\circ} 20.017$ que modifica el Código de Aguas de 1981 (мOP, 2005), de donde se desprenden las ecuaciones (1) y (2) para calcular la PNU a pagar por derechos consuntivos y no consuntivos, respectivamente:

$$
\begin{gathered}
P_{\mathrm{C}}=\gamma_{\mathrm{C}} \cdot Q_{\mathrm{C}} \cdot f \\
P_{\mathrm{NC}}=\gamma_{\mathrm{NC}} \cdot Q_{\mathrm{NC}} \cdot H \cdot f
\end{gathered}
$$

donde:

$P_{\mathrm{C}}$ : patente para DAA consuntivos (en UTM ${ }^{12}$ ).

$P_{\mathrm{NC}}$ : patente para DAA no consuntivos (en UTM).

$\gamma_{\mathrm{C}}: \quad$ constante macrozonal para DAA consuntivos $(1,6$ norte-centro; 0,2 centro-sur; 0,1 sur-austral).

$\gamma_{\mathrm{NC}}$ : constante macrozonal para DAA no consuntivos ( 0,33 de Chiloé al norte; 0,22 de Palena al sur, ambas provincias pertenecientes a la Región de Los Lagos).

$Q_{\mathrm{C}}: \quad$ caudal medio sin uso para DAA consuntivos (en litros por segundo).

$Q_{\mathrm{NC}}$ : caudal medio sin uso para DAA no consuntivos (en metros cúbicos por segundo).

$H$ : desnivel entre los puntos de captación y de restitución (en metros) ${ }^{13}$.

$f: \quad$ factor de progresividad ( 1 desde el $1^{\circ}$ hasta el $5^{\circ}$ año de cobro; 2 desde el $6^{\circ}$ al $10^{\circ} ; 4 \operatorname{del} 11^{\circ}$ en adelante).

Ambas ecuaciones están diseñadas para derechos de ejercicio permanente y continuo. Sin perjuicio de lo anterior, en el diseño de la patente se estableció que:

i) Los derechos eventuales pagan un tercio de la patente que pagaría un derecho de ejercicio permanente equivalente.

ii) En los derechos con distribución de caudales diferenciada a lo largo del año, se considera el promedio anual.

\footnotetext{
11 Otros usos no consuntivos, como el acuícola o la refrigeración industrial, se ignoran por representar una fracción mínima en comparación con el uso hidroeléctrico.

12 Unidad tributaria mensual: unidad de cuenta usada en Chile para efectos tributarios y de multas, que se reajusta mensualmente según la inflación.

${ }^{13}$ Esta variable no puede ser inferior a $10 \mathrm{~m}$, por lo que se utiliza este valor para desniveles inferiores.
} 
iii) En los derechos de ejercicio discontinuo, se suman solo los meses con caudal positivo y se dividen en 12 meses.

iv) No se hace diferencia entre las patentes para aguas superficiales y subterráneas.

v) Los derechos otorgados con carácter provisional también se encuentran afectos a pago de patente.

Finalmente, la eficacia de la PNU se determinó mediante el criterio "Diferencia entre el cobro de la PNU y el precio de mercado de un derecho" (criterio C); en consecuencia, mientras mayor sea esta brecha, siendo el precio de mercado el límite superior, mayor será la posibilidad de que los propietarios paguen la patente y sigan manteniendo sus derechos sin uso. En caso contrario, mientras menor sea la brecha anterior, o bien en cualquier situación en que el precio de mercado sea el límite inferior de la brecha, menor será la posibilidad de que los propietarios decidan mantener sus derechos sin uso.

\section{III}

\section{Resultados empíricos y discusión}

\section{Patentes cobradas en comparación con las recaudadas}

El porcentaje de pago ha aumentado a través de los sucesivos procesos de aplicación de la patente, comenzando con el $67 \%$ respecto de lo cobrado en 2007 y ascendiendo al 81,4\% en 2009. No obstante, el porcentaje de la cantidad de derechos que pagaron la patente con relación al total afecto disminuye del 63,4\% en 2007 al 50,9\% en 2009 (véase el cuadro 1). Esta situación se explica porque:

i) ha habido renuncias ${ }^{14}$ a la propiedad de derechos, se han redistribuido derechos a nuevos propietarios y se ha comenzado a utilizar algunos derechos que estaban en desuso;

\footnotetext{
${ }^{14}$ La renuncia a un DAA se estableció en la Ley $\mathrm{N}^{\mathrm{o}} 20.017$ y, tal como lo indica su nombre, consiste en que una persona renuncia a ser propietaria de un derecho. En la renuncia, el derecho se extingue y el agua asociada a este queda disponible; distinto es lo que ocurre en el caso de no pago de la PNU, en que el DAA es rematado.
}

ii) las patentes más costosas cobradas por DAA no consuntivos, en general, se han continuado pagando; $y$

iii) en los procesos de cobro de 2008 y 2009 se incorporaron al listado nuevos derechos afectos a patentes más baratas —coloquialmente llamados “derechos más pequeños"-, lo que ha derivado en una disminución progresiva de la patente media por derecho afecto y en poca variabilidad de la patente media por derecho pagado (véase el cuadro 1).

Por otra parte, las patentes cobradas en 2009 son inferiores a las de 2008 en 2.943.626 dólares (véase el cuadro 1), cifra que representa una cantidad de derechos que salieron del listado porque fueron renunciados, vendidos o se comenzaron a utilizar. En otras palabras, para este grupo de DAA, la PNU tuvo éxito en su objetivo, salvo en el caso de aquellos derechos que salieron del listado porque sus propietarios encontraron una forma de evadir la patente, como se verá más adelante.

Un desglose más específico de los datos (véase el gráfico 2) permite observar que el total de patentes cobradas por los derechos consuntivos es similar en 2007 y

\begin{tabular}{|c|c|c|c|c|c|c|c|c|}
\hline \multirow{2}{*}{$\begin{array}{l}\text { Proceso } \\
\text { de cobro }\end{array}$} & \multicolumn{3}{|c|}{$\begin{array}{l}\text { Patentes } \\
\text { (en dólares) }\end{array}$} & \multicolumn{3}{|c|}{$\begin{array}{l}\text { Cantidad de derechos } \\
\quad \text { (en unidades) }\end{array}$} & \multicolumn{2}{|c|}{$\begin{array}{l}\text { Patente media por } \\
\text { derecho (en dólares) }\end{array}$} \\
\hline & Cobradas & Recaudadas & Porcentaje & Afectos & Pagados & Porcentaje & Afecto & Pagado \\
\hline 2007 & 25349632 & 16971827 & 67,0 & 1302 & 826 & 63,4 & 19470 & 20547 \\
\hline 2008 & 28767544 & 21097355 & 73,3 & 1554 & 959 & 61,7 & 18512 & 21999 \\
\hline 2009 & 25823918 & 21017428 & 81,4 & 2006 & 1021 & 50,9 & 12873 & 20585 \\
\hline
\end{tabular}

Fuente: elaboración propia sobre la base de Dirección General de Aguas (DGA), Bases de datos del listado de derechos de aprovechamiento de aguas afectos a pago de patente por no uso, procesos 2007 a 2010, Santiago de Chile, Ministerio de Obras Públicas (MOP), 2010. 
2008, mientras que en 2009 disminuye, en tanto que para los derechos no consuntivos ha sucedido lo inverso, pese a que la cantidad de derechos afectos, tanto consuntivos como no consuntivos, ha aumentado (véase el gráfico 3). Respecto de las patentes recaudadas, en el caso de los DAA no consuntivos el pago siempre ha superado el 95\%, mientras que el pago en los derechos consuntivos recién alcanza al 50\% en 2009. Esto indica, al menos, que la PNU está teniendo éxito en los DAA consuntivos, y que los datos disponibles no permiten aún establecer una tendencia en el caso de los no consuntivos.

De forma similar, se observa que los DAA consuntivos han ido desapareciendo del listado de derechos afectos a patentes más caras (véase el cuadro 2), no así los derechos no consuntivos que tienden a aparecer en el listado año tras año (véase el cuadro 3). Esto se corrobora examinando la clasificación correspondiente a 2010 (última columna de los cuadros 2 y 3), donde solo

GRÁFICO 2

Comparación de ingreso por PNU cobradas y recaudadas, 2007-2009

(En millones de dólares)

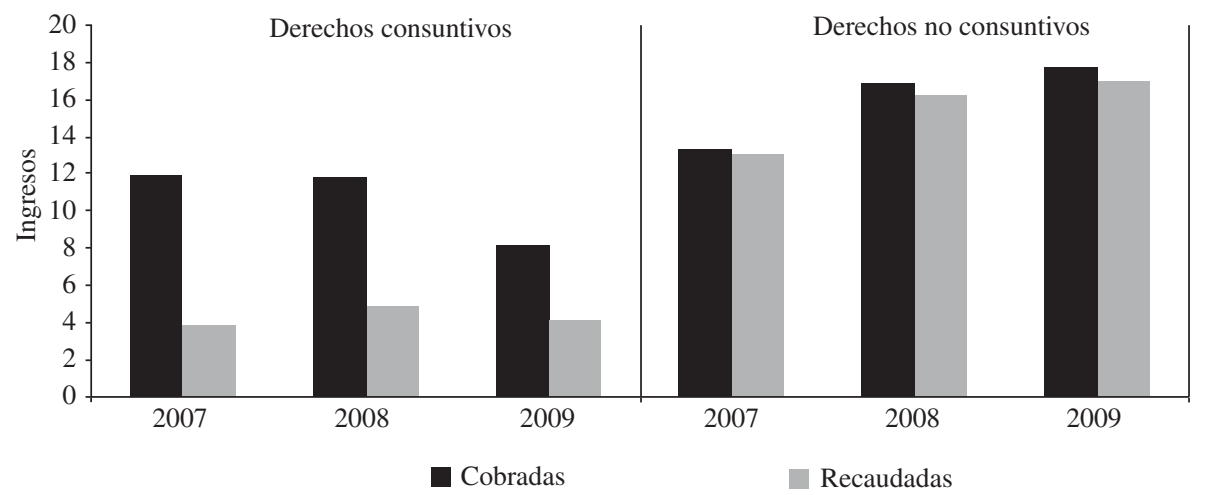

Fuente: elaboración propia sobre la base de Dirección General de Aguas (DGA), Bases de datos del listado de derechos de aprovechamiento de aguas afectos a pago de patente por no uso, procesos 2007 a 2010, Santiago de Chile, Ministerio de Obras Públicas (MOP), 2010.

PNU: patente por no uso.

GRÁFICO 3
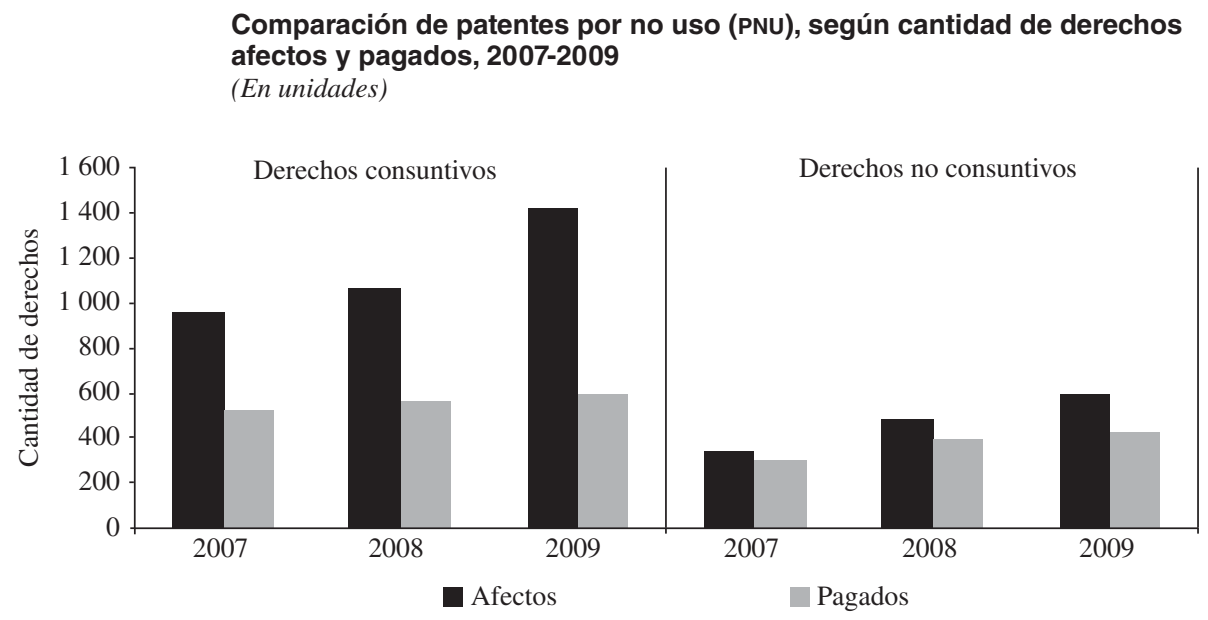

Fuente: elaboración propia sobre la base de Dirección General de Aguas (DGA), Bases de datos del listado de derechos de aprovechamiento de aguas afectos a pago de patente por no uso, procesos 2007 a 2010, Santiago de Chile, Ministerio de Obras Públicas (MOP), 2010. 
CUADRO 2

Mayores cobros de patente por no uso (PNU), derechos consuntivos, 2007-2010

\begin{tabular}{|c|c|c|c|c|c|c|c|}
\hline \multirow{2}{*}{ Propietario } & \multirow{2}{*}{ Región } & \multirow{2}{*}{$\begin{array}{c}\text { Patente } \\
\text { (en dólares) }\end{array}$} & \multirow{2}{*}{$\begin{array}{l}\text { Caudal } \\
(\text { en } l / s)\end{array}$} & \multicolumn{4}{|c|}{ Clasificación } \\
\hline & & & & 2007 & 2008 & 2009 & 2010 \\
\hline María Estela García Constans & Valparaíso & 4498101 & 37787 & 1 & - & - & - \\
\hline Valle Rapel S. A. & Valparaíso & 3594988 & 30200 & - & 1 & - & - \\
\hline Valle Central S. A. & Valparaíso & 904699 & 7600 & - & 2 & - & - \\
\hline Fisco. Dirección de Obras Hidráulicas & El Biobío & 644797 & 43333 & 2 & - & - & - \\
\hline Fisco. Dirección de Obras Hidráulicas & El Biobío & 644797 & 43333 & 3 & - & - & - \\
\hline Fisco. Dirección de Obras Hidráulicas & El Biobío & 644797 & 43333 & 4 & - & - & - \\
\hline Usuarios del Canal Biobío Sur & El Biobío & 578313 & 38865 & 5 & - & - & - \\
\hline Agrícola y Comercial Los Lleuques Ltda. & Metropolitana & 553533 & 4650 & 6 & - & - & - \\
\hline Inversiones El Álamo S. A. & Metropolitana & 462765 & 3888 & - & 3 & 1 & - \\
\hline Alberto Acuña Puchi y Otros & La Araucanía & 446398 & 30000 & 7 & 4 & 2 & 1 \\
\hline Proyectos de Aysén S. A. & Aysén & 446398 & 60000 & 8 & 5 & 3 & - \\
\hline Energía Austral Ltda. & & & & - & - & - & 2 \\
\hline Exploraciones, Inversiones y Asesorías Manantiales S. A. & Metropolitana & 404920 & 3402 & - & - & - & 3 \\
\hline Proyectos de Aysén S. A. & Aysén & 371998 & 5,000 & 9 & 6 & 4 & - \\
\hline Energía Austral Ltda. & & & & - & - & - & 4 \\
\hline Fisco. Dirección de Riego & La Araucanía & 314586 & 21142 & 10 & - & - & - \\
\hline María Estela García Constans & Valparaíso & 312677 & 7880 & 11 & - & - & - \\
\hline Juan Landerretche Díaz y Otros & El Biobío & 295366 & 19850 & - & 7 & - & - \\
\hline Comercial San Alberto Ltda. & Metropolitana & 273791 & 2300 & - & 8 & - & - \\
\hline Valle Rapel S. A. & Valparaíso & 249983 & 6300 & - & 9 & - & - \\
\hline Inversiones Quintay S. A. & Metropolitana & 231383 & 1944 & - & - & - & 5 \\
\hline Agrícola Las Acacias del Aconcagua S. A. & Metropolitana & 231383 & 1944 & - & - & - & 6 \\
\hline Inversiones Quintay S. A. & Metropolitana & 219479 & 1844 & - & 10 & 5 & - \\
\hline Inversiones Arlequín Ltda. & Coquimbo & 158719 & 4000 & - & - & - & 7 \\
\hline Inversiones Arlequín Ltda. & Valparaíso & 148799 & 1250 & 12 & 11 & 6 & 8 \\
\hline Gonzalo Donato Quezada Pressac & Metropolitana & 140109 & 1177 & - & - & 7 & - \\
\hline Hidroeléctrica Guardia Vieja S. A. & Valparaíso & 134068 & 1126 & 13 & - & - & - \\
\hline Agrícola Los Retoños S. A. & Valparaíso & 122015 & 1025 & 14 & 12 & - & - \\
\hline Jorge Schmidt y Cía. Ltda. & & & & - & - & 8 & - \\
\hline Humberto Einar y Otro & Valparaíso & 119039 & 1000 & - & - & 9 & - \\
\hline
\end{tabular}

Fuente: elaboración propia sobre la base de Dirección General de Aguas (DGA), Bases de datos del listado de derechos de aprovechamiento de aguas afectos a pago de patente por no uso, procesos 2007 a 2010, Santiago de Chile, Ministerio de Obras Públicas (MOP), 2010.

Nota: los registros marcados en gris corresponden a derechos de aprovechamiento de aguas cuyo titular cambió a través de los procesos de cobro de patente por no utilización.

1/s: litros por segundo.

2 de 30 derechos consuntivos aparecen en el listado para procesos anteriores, mientras que otros dos figuraban en procesos anteriores, pero en manos de un propietario diferente - fueron vendidos o cedidos y puede suponerse que pronto se comenzarán a utilizar. En cambio, entre los no consuntivos son únicamente tres los derechos que han estado por primera vez en el listado para el proceso de 2010, y solo otros dos ya no se encuentran en el listado para este año. El resto, son derechos que han estado anteriormente en el listado, ya sea en manos de 
CUADRO 3

Mayores cobros de patente por no uso (PNU), derechos no consuntivos, 2007-2010

\begin{tabular}{|c|c|c|c|c|c|c|c|}
\hline \multirow{2}{*}{ Propietario } & \multirow{2}{*}{ Región } & \multirow{2}{*}{$\begin{array}{c}\text { Patente } \\
\text { (en dólares) }\end{array}$} & \multirow{2}{*}{$\begin{array}{l}\text { Caudal } \\
\text { (en l/s) }\end{array}$} & \multicolumn{4}{|c|}{ Clasificación } \\
\hline & & & & 2007 & 2008 & 2009 & 2010 \\
\hline ENDESA S. A. & Los Lagos & 3526876 & 850 & 1 & 1 & 1 & 1 \\
\hline Juan Wenke Williams & Valparaíso & 2393807 & 2 & - & 2 & - & - \\
\hline ENDESA S. A. & El Biobío & 1189538 & 255 & - & - & - & 2 \\
\hline Beatriz Cortés Torres & El Maule & 618707 & 60 & 2 & 3 & - & - \\
\hline Inversiones Arlequín Ltda. & & & & - & - & 2 & - \\
\hline Hidroeléctrica Centinela Ltda. & & & & - & - & - & 3 \\
\hline ENDESA S. A. & Los Ríos & 478276 & 48 & - & 4 & 3 & 4 \\
\hline ENDESA S. A. & El Maule & 472623 & 25 & 3 & 5 & 4 & 5 \\
\hline ENDESA S. A. & Los Lagos & 438251 & 255 & 4 & 6 & 5 & 6 \\
\hline AES Gener S. A. & Metropolitana & 407365 & 61 & - & 7 & - & - \\
\hline AES Gener S. A. & Metropolitana & 405106 & 15 & - & 8 & 6 & 7 \\
\hline ENDESA S. A. & El Maule & 392830 & 80 & 5 & - & - & - \\
\hline Colbún S. A. & & & & - & 9 & 7 & 8 \\
\hline AES Gener S. A. & Metropolitana & 353915 & 31 & - & 10 & 8 & 9 \\
\hline Hernán Lacalle Soza y Otros & Los Lagos & 318192 & 270 & 6 & - & - & - \\
\hline Colbún S. A. & & & & - & 11 & 9 & 10 \\
\hline Chilgener S. A. & El Maule & 285784 & 19 & 7 & - & - & - \\
\hline AES Gener S. A. & & & & - & 12 & 10 & 11 \\
\hline Mediterráneo S. A. & Los Lagos & 257034 & 75 & - & - & - & 12 \\
\hline Jorge Wachholtz Buchholtz & O’Higgins & 243063 & 30 & - & - & - & 13 \\
\hline CGE Generación S. A. & El Maule & 239994 & 23 & 8 & 13 & 11 & 14 \\
\hline ENDESA S. A. & Los Ríos & 223717 & 68 & - & 14 & 12 & 15 \\
\hline AES Gener S. A. & Metropolitana & 205622 & 25 & - & 15 & 13 & 16 \\
\hline CGE Generación S. A. & El Biobío & 204272 & 52 & - & 16 & 14 & 17 \\
\hline AES Gener S. A. & Metropolitana & 200343 & 30 & - & - & 15 & 18 \\
\hline CGE Generación S. A. & El Maule & 190031 & 18 & 9 & 17 & 16 & 19 \\
\hline AES Gener S. A. & Metropolitana & 183651 & 36 & - & 18 & - & 20 \\
\hline Compañía Forestal Chiloé & Los Lagos & 178861 & 47 & 10 & 19 & 17 & - \\
\hline Inversiones y Desarrollo Sur S. A. & & & & - & - & - & 21 \\
\hline Forestal Cholguán S. A. & El Biobío & 172354 & 130 & - & - & 18 & 22 \\
\hline
\end{tabular}

Fuente: elaboración propia sobre la base de Dirección General de Aguas (DGA), Bases de datos del listado de derechos de aprovechamiento de aguas afectos a pago de patente por no uso, procesos 2007 a 2010, Santiago de Chile, Ministerio de Obras Públicas (MoP), 2010.

Nota: los registros marcados en gris corresponden a DAA cuyo titular cambió a través de los procesos de cobro de patente por no utilización.

1/s: litros por segundo.

un único propietario o bien en manos de dos e incluso tres propietarios diferentes. Un ejemplo se aprecia en los registros cuarto, quinto y sexto del cuadro 3 , en que cambia el propietario a través de los años ("Beatriz Cortés Torres" en 2007 y 2008, "Inversiones Arlequín Ltda." en 2009 e "Hidroeléctrica Centinela Ltda." en 2010), lo que indica que el mismo derecho se ha mantenido sin uso por cuatro años en manos de distintos propietarios.

Si bien el total de patentes cobradas por DAA consuntivos ha sido menor que el total por no consuntivos (véase el gráfico 2), es importante considerar el caudal (véase el gráfico 4) dado que hay grandes diferencias 
entre ambos tipos de derechos. Estas diferencias no se reflejan fielmente en las patentes cobradas, debido a que la patente para los derechos consuntivos se calcula por caudal en litros por segundo, mientras que para los no consuntivos se calcula en metros cúbicos por segundo (véanse las ecuaciones (1) y (2)), es decir, la diferencia es una razón de 1.000 a 1.
Como se esperaba, las renuncias solo han tenido lugar con respecto a derechos afectos a patente, siendo otro aspecto que reafirma el mayor éxito de la PNU en los derechos consuntivos que en los no consuntivos, ascendiendo a 4.365 .908 dólares y $58,4 \mathrm{~m}^{3} / \mathrm{s}$ (véase el cuadro 4), y 28.476 dólares y $11,1 \mathrm{~m}^{3} / \mathrm{s}$ (véase el cuadro 5), respectivamente.

GRÁFICO 4

Comparación de patentes por no uso (PNU) según caudal afecto y pagado, 2007-2009 (En metros cúbicos por segundo: $\mathrm{m}^{3} / \mathrm{s}$ )

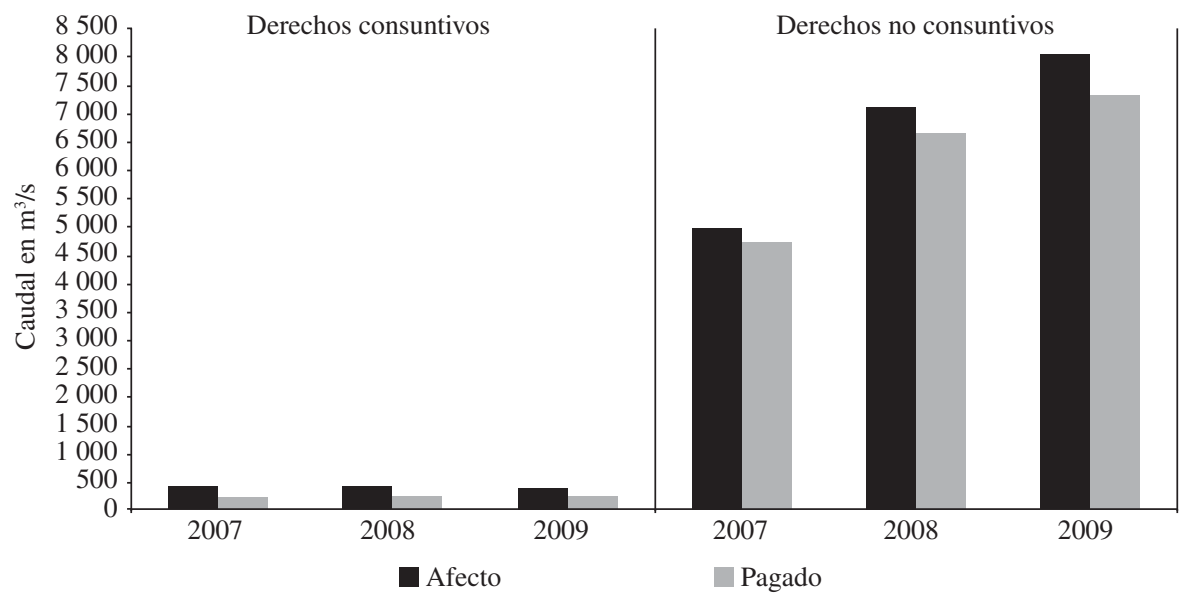

Fuente: elaboración propia sobre la base de Dirección General de Aguas (DGA), Bases de datos del listado de derechos de aprovechamiento de aguas afectos a pago de patente por no uso, procesos 2007 a 2010, Santiago de Chile, Ministerio de Obras Públicas (MOP), 2010.

CUADRO 4

Renuncias a DAA consuntivos, 2007-2010

(En dólares)

\begin{tabular}{|c|c|c|c|c|}
\hline Propietario & Región & Fuente & $\begin{array}{l}\text { Caudal } \\
(\text { en } l / s)\end{array}$ & $\begin{array}{l}\text { Patente equivalente } \\
\text { (en dólares) }\end{array}$ \\
\hline Valle Rapel S.A. & Valparaíso & Río Rapel & 28527 & 3395836 \\
\hline Humberto Benedetti Rosenqvist & Valparaíso & Sin nombre & 4570 & 544010 \\
\hline Valle Rapel S.A. & Valparaíso & Río Rapel & 5579 & 221376 \\
\hline Bosques Cautín & La Araucanía & Río Toltén & 3500 & 52080 \\
\hline Corpora Agrícola S.A. & Valparaíso & Río Aconcagua & 213 & 25296 \\
\hline Dora Elena Oelckers & Los Lagos & Río Pilmaiquén & 10000 & 24797 \\
\hline Agrícola Paiquén & Valparaíso & Río Aconcagua & 208 & 24760 \\
\hline Bosques Cautín & La Araucanía & Río Imperial & 1500 & 22320 \\
\hline Ganadera Río Caleta Ltda. & Magallanes & Río La Caleta & 1951 & 14515 \\
\hline Corpora Agrícola S.A. & Valparaíso & Río Aconcagua & 255 & 10118 \\
\hline Agrícola Paiquén & Valparaíso & Río Aconcagua & 250 & 9920 \\
\hline Bosques Cautín & La Araucanía & Río Cholchol & 667 & 9917 \\
\hline Margarita Yutronich & Magallanes & Río Blanco & 841 & 6257 \\
\hline José Irarrázaval Larraín & La Araucanía & Estero La Gaviota & 219 & 3255 \\
\hline Rolando Hott Marquard & La Araucanía & Estero Huilío & 88 & 1302 \\
\hline Domingo Couso & Los Lagos & Lago Llanquihue & 20 & 149 \\
\hline Total & & & 58386 & 4365908 \\
\hline
\end{tabular}

Fuente: Dirección General de Aguas (DGA), Informe sobre patente por no uso de derechos de aprovechamiento de aguas, Santiago de Chile, Ministerio de Obras Públicas (MOP), 2010.

DAA: derechos de aprovechamiento de aguas.

1/s: litros por segundo. 
CUADRO 5

Renuncias a DAA no consuntivos, $\mathbf{2 0 0 7 - 2 0 1 0}$

(En dólares)

\begin{tabular}{|c|c|c|c|c|}
\hline Propietario & Región & Fuente & $\begin{array}{l}\text { Caudal } \\
(\text { en } l / s)\end{array}$ & $\begin{array}{l}\text { Patente equivalente } \\
\text { (en dólares) }\end{array}$ \\
\hline Soc. Agrícola y Forestal Degenfield & Los Lagos & Río Cahulnalhue & 4259 & 26144 \\
\hline Rolando Polh Marquard & La Araucanía & Río Palguín & 2000 & 982 \\
\hline Soc. Agrícola y Forestal Degenfield & Los Lagos & Río Cahulnalhue & 1752 & 513 \\
\hline Bosques Cautín & La Araucanía & Río Imperial & 1500 & 368 \\
\hline Bosques Cautín & La Araucanía & Río Cholchol & 1083 & 346 \\
\hline Bosques Cautín & La Araucanía & Río Toltén & 500 & 123 \\
\hline Total & & & 11094 & 28476 \\
\hline
\end{tabular}

Fuente: Dirección General de Aguas (DGA), Informe sobre patente por no uso de derechos de aprovechamiento de aguas, Santiago de Chile, Ministerio de Obras Públicas (MOP), 2010.

DAA: derechos de aprovechamiento de aguas.

1/s: litros por segundo.

A lo largo del territorio chileno existen diferencias importantes en los totales macrozonales de patentes cobradas por derechos consuntivos (véanse los cuadros 6,7 y 8). En los distintos procesos, la mayor parte del total cobrado corresponde a la macrozona norte-centro (zona árida y semiárida), debido a que

CUADRO 6

Total regional de patentes por no uso (PNU) cobradas y recaudadas, derechos consuntivos, 2007

\begin{tabular}{|c|c|c|c|c|c|c|c|c|c|}
\hline \multirow[t]{2}{*}{ Región } & \multicolumn{3}{|c|}{$\begin{array}{l}\text { Patentes } \\
\text { (en dólares) }\end{array}$} & \multicolumn{3}{|c|}{$\begin{array}{l}\text { Cantidad de DAA } \\
\text { (en unidades) }\end{array}$} & \multicolumn{3}{|c|}{$\begin{array}{l}\text { Caudal } \\
\left(\text { en } \mathrm{m}^{3} / \mathrm{s}\right)\end{array}$} \\
\hline & Cobradas & Recaudadas & Porcentaje & Afectos & Pagados & Porcentaje & Afecto & Pagado & Porcentaje \\
\hline Arica y Parinacota & 3333 & 3333 & 100,0 & 1 & 1 & 100,0 & 0028 & 0028 & 100,0 \\
\hline Tarapacá & 117992 & 116682 & 98,9 & 23 & 21 & 91,3 & 0991 & 0980 & 98,9 \\
\hline Antofagasta & 437185 & 428674 & 98,1 & 59 & 55 & 93,2 & 3673 & 3601 & 98,1 \\
\hline Atacama & 594777 & 406575 & 68,4 & 97 & 63 & 64,9 & 4996 & 3415 & 68,4 \\
\hline Coquimbo & 475872 & 396580 & 83,3 & 47 & 38 & 80,9 & 3998 & 3332 & 83,3 \\
\hline Valparaíso & 6367626 & 777629 & 12,2 & 116 & 53 & 45,7 & 62240 & 7917 & 12,7 \\
\hline Metropolitana & 1312339 & 309098 & 23,6 & 115 & 47 & 40,9 & 11687 & 2577 & 22,0 \\
\hline Macrozona norte-centro & 9309123 & 2438571 & 26,2 & 458 & 278 & 60,7 & 87612 & 21850 & 24,9 \\
\hline O’Higgins & 38744 & 14515 & 37,5 & 31 & 14 & 45,2 & 2681 & 0976 & 36,4 \\
\hline El Maule & 125102 & 34489 & 27,6 & 65 & 19 & 29,2 & 11171 & 3159 & 28,3 \\
\hline El Biobío & 86364 & 13612 & 15,8 & 14 & 5 & 35,7 & 5923 & 0915 & 15,4 \\
\hline La Araucanía & 879953 & 236726 & 26,9 & 135 & 64 & 47,4 & 65644 & 20327 & 31,0 \\
\hline Macrozona centro-sur & 1130163 & 299343 & 26,5 & 245 & 102 & 41,6 & 85418 & 25376 & 29,7 \\
\hline Los Ríos & 150911 & 101582 & 67,3 & 104 & 72 & 69,2 & 23335 & 14810 & 63,5 \\
\hline Los Lagos & 159532 & 82670 & 51,8 & 45 & 31 & 68,9 & 28585 & 11588 & 40,5 \\
\hline Aysén & 932360 & 895497 & 96,0 & 21 & 8 & 38,1 & 145498 & 140208 & 96,4 \\
\hline Magallanes & 299019 & 53402 & 17,9 & 85 & 30 & 35,3 & 50607 & 10592 & 20,9 \\
\hline Macrozona sur-austral & 1541822 & 1133152 & 73,5 & 255 & 141 & 55,3 & 248025 & 177197 & 71,4 \\
\hline Total & 11981107 & 3871065 & 32,3 & 958 & 521 & 54,4 & 421055 & 224423 & 53,3 \\
\hline
\end{tabular}

Fuente: elaboración propia sobre la base de Dirección General de Aguas (DGA), Bases de datos del listado de derechos de aprovechamiento de aguas afectos a pago de patente por no uso, procesos 2007 a 2010, Santiago de Chile, Ministerio de Obras Públicas (MOP), 2010.

DAA: derechos de aprovechamiento de aguas.

$\mathrm{m}^{3} / \mathrm{s}$ : metros cúbicos por segundo. 


\begin{tabular}{|c|c|c|c|c|c|c|c|c|c|}
\hline \multirow{2}{*}{ Región } & \multicolumn{3}{|c|}{$\begin{array}{l}\text { Patentes } \\
\text { (en dólares) }\end{array}$} & \multicolumn{3}{|c|}{$\begin{array}{l}\text { Cantidad de derechos } \\
\text { (en unidades) }\end{array}$} & \multicolumn{3}{|c|}{$\begin{array}{l}\text { Caudal } \\
\left(\text { en } \mathrm{m}^{3} / \mathrm{s}\right)\end{array}$} \\
\hline & Cobradas & Recaudadas & Porcentaje & Afectos & Pagados & Porcentaje & Afecto & Pagado & Porcentaje \\
\hline Arica y Parinacota & 3333 & 3333 & 100,0 & 1 & 1 & 100,0 & 0028 & 0028 & 100,0 \\
\hline Tarapacá & 117992 & 115016 & 97,5 & 23 & 22 & 95,7 & 0991 & 0966 & 97,5 \\
\hline Antofagasta & 644254 & 642111 & 99,7 & 83 & 82 & 98,8 & 5412 & 5394 & 99,7 \\
\hline Atacama & 586801 & 351654 & 59,9 & 95 & 53 & 55,8 & 4929 & 2954 & 59,9 \\
\hline Coquimbo & 607703 & 447298 & 73,6 & 68 & 41 & 60,3 & 5105 & 3758 & 73,6 \\
\hline Valparaíso & 5376561 & 835488 & 15,5 & 137 & 67 & 48,9 & 53000 & 9797 & 18,5 \\
\hline Metropolitana & 1752758 & 1034532 & 59,0 & 148 & 51 & 34,5 & 15934 & 8803 & 55,2 \\
\hline Macrozona norte-centro & 9089402 & 3429432 & 37,7 & 555 & 317 & 57,1 & 85400 & 31700 & 37,1 \\
\hline O'Higgins & 168148 & 155314 & 92,4 & 41 & 29 & 70,7 & 12444 & 11582 & 93,1 \\
\hline El Maule & 138425 & 31158 & 22,5 & 62 & 13 & 21,0 & 12013 & 3135 & 26,1 \\
\hline El Biobío & 85472 & 14729 & 17,2 & 16 & 9 & 56,3 & 5863 & 0990 & 16,9 \\
\hline La Araucanía & 862022 & 122876 & 14,3 & 134 & 54 & 40,3 & 64439 & 12576 & 19,5 \\
\hline Macrozona centro-sur & 1254067 & 324076 & 25,8 & 253 & 105 & 41,5 & 94758 & 28282 & 29,8 \\
\hline Los Ríos & 146136 & 111672 & 76,4 & 101 & 71 & 70,3 & 22026 & 16630 & 75,5 \\
\hline Los Lagos & 161090 & 82664 & 51,3 & 52 & 34 & 65,4 & 28795 & 11466 & 39,8 \\
\hline Aysén & 932360 & 893332 & 95,8 & 21 & 7 & 33,3 & 145498 & 139917 & 96,2 \\
\hline Magallanes & 284504 & 53105 & 18,7 & 86 & 31 & 36,0 & 48656 & 10552 & 21,7 \\
\hline Macrozona sur-austral & 1524089 & 1140772 & 74,8 & 260 & 143 & 55,0 & 244975 & 178565 & 72,9 \\
\hline Total & 11867558 & 4894280 & 41,2 & 1068 & 565 & 52,9 & 425133 & 238547 & 56,1 \\
\hline
\end{tabular}

Fuente: elaboración propia sobre la base de Dirección General de Aguas (DGA), Bases de datos del listado de derechos de aprovechamiento de aguas afectos a pago de patente por no uso, procesos 2007 a 2010, Santiago de Chile, Ministerio de Obras Públicas (MoP), 2010.

DAA: derechos de aprovechamiento de aguas.

$\mathrm{m}^{3} / \mathrm{s}$ : metros cúbicos por segundo.

en esta parte de Chile la ecuación para calcular la PNU se pondera por una constante de 1,6, mientras que en las macrozonas centro-sur y sur-austral se pondera por constantes de 0,2 y 0,1 , respectivamente (véase la ecuación (1)), cuyo resultado es que el total de patentes cobradas es comparativamente menor en estas dos últimas macrozonas.

En cuanto a la recaudación, la disponibilidad de agua según la latitud del territorio chileno (con grados de escasez decrecientes de norte a sur) y las constantes macrozonales para calcular la patente respecto de DAA consuntivos, provocan que difieran los porcentajes de pago entre regiones de una misma macrozona. Un efecto de esta diferencia se puede ejemplificar con el caso de dos regiones vecinas y similares en sus condiciones hidrológicas: Metropolitana y O'Higgins. En el proceso de 2009 (véase el cuadro 8) se observa que el caudal afecto a PNU es similar $\left(15,39\right.$ y $11,42 \mathrm{~m}^{3} / \mathrm{s}$, respectivamente), pero la suma de patentes cobradas muy distinta (1.688.064 y 153.158 dólares, respectivamente) y, en concordancia, el porcentaje de pago en relación con lo cobrado también es muy dispar $(31,2 \%$ y $87,2 \%$, de modo respectivo).

Por otra parte, en lo que se refiere a los DAA no consuntivos, el porcentaje de pago sobre las patentes cobradas es siempre alto en las distintas regiones, no siendo las constantes de cálculo de la patente (véase la ecuación (2)) un factor determinante. Además, en los derechos no consuntivos el cobro de patentes se concentra, a diferencia de los consuntivos, en las macrozonas centro-sur y sur-austral (véanse los cuadros 9, 10 y 11), por dos razones:

i) mientras que en la macrozona norte-centro están exentos de pago de patente los derechos cuya constitución original sea menor a 10 y 100 l/s, con relación a derechos consuntivos y no consuntivos, respectivamente, en las otras macrozonas estos valores son de 50 y 500 l/s, por lo que una mayor cantidad de derechos queda fuera del listado de cobro desde la Región de O’Higgins al sur; y 
CUADRO 8

Total regional de patentes por no uso (PNU) cobradas y recaudadas, derechos consuntivos, 2009

\begin{tabular}{|c|c|c|c|c|c|c|c|c|c|}
\hline \multirow{2}{*}{ Región } & \multicolumn{3}{|c|}{$\begin{array}{l}\text { Patentes } \\
\text { (en dólares) }\end{array}$} & \multicolumn{3}{|c|}{$\begin{array}{l}\text { Cantidad de derechos } \\
\text { (en unidades) }\end{array}$} & \multicolumn{3}{|c|}{$\begin{array}{l}\text { Caudal } \\
\left(\text { en } \mathrm{m}^{3} / \mathrm{s}\right)\end{array}$} \\
\hline & Cobradas & Recaudadas & Porcentaje & Afectos & Pagados & Porcentaje & Afecto & Pagado & Porcentaje \\
\hline Arica y Parinacota & 35871 & 13253 & 36,9 & 6 & 4 & 66,7 & 0508 & 0198 & 39,0 \\
\hline Tarapacá & 129646 & 115123 & 88,8 & 27 & 24 & 88,9 & 1089 & 0967 & 88,8 \\
\hline Antofagasta & 726190 & 724047 & 99,7 & 84 & 83 & 98,8 & 6125 & 6107 & 99,7 \\
\hline Atacama & 606220 & 346881 & 57,2 & 109 & 51 & 46,8 & 5359 & 2914 & 54,4 \\
\hline Coquimbo & 516455 & 241057 & 46,7 & 58 & 33 & 56,9 & 4339 & 2025 & 46,7 \\
\hline Valparaíso & 1421693 & 644577 & 45,3 & 181 & 72 & 39,8 & 14852 & 6784 & 45,7 \\
\hline Metropolitana & 1688064 & 525992 & 31,2 & 163 & 46 & 28,2 & 15390 & 4461 & 29,0 \\
\hline Macrozona norte-centro & 5124138 & 2610930 & 51,0 & 628 & 313 & 49,8 & 47663 & 23457 & 49,2 \\
\hline O'Higgins & 153158 & 133483 & 87,2 & 44 & 26 & 59,1 & 11421 & 10021 & 87,7 \\
\hline El Maule & 191522 & 81816 & 42,7 & 60 & 13 & 21,7 & 23815 & 14896 & 62,5 \\
\hline El Biobío & 152559 & 29969 & 19,6 & 27 & 14 & 51,9 & 10371 & 2133 & 20,6 \\
\hline La Araucanía & 851927 & 102654 & 12,0 & 187 & 41 & 21,9 & 63266 & 9499 & 15,0 \\
\hline Macrozona centro-sur & 1349166 & 347922 & 25,8 & 318 & 94 & 29,6 & 108873 & 36548 & 33,6 \\
\hline Los Ríos & 254224 & 173932 & 68,4 & 214 & 121 & 56,5 & 38196 & 26275 & 68,8 \\
\hline Los Lagos & 204346 & 48331 & 23,7 & 151 & 46 & 30,5 & 28965 & 6629 & 22,9 \\
\hline Aysén & 933759 & 891431 & 95,5 & 25 & 5 & 20,0 & 146024 & 139150 & 95,3 \\
\hline Magallanes & 276200 & 18379 & 6,7 & 79 & 16 & 20,3 & 47175 & 3114 & 6,6 \\
\hline Macrozona sur-austral & 1668529 & 1132073 & 67,8 & 469 & 188 & 40,1 & 260360 & 175169 & 67,3 \\
\hline Total & 8141833 & 4090926 & 50,2 & 1415 & 595 & 42,0 & 416895 & 235174 & 56,4 \\
\hline
\end{tabular}

Fuente: elaboración propia sobre la base de Dirección General de Aguas (DGA), Bases de datos del listado de derechos de aprovechamiento de aguas afectos a pago de patente por no uso, procesos 2007 a 2010, Santiago de Chile, Ministerio de Obras Públicas (MoP), 2010.

DAA: derechos de aprovechamiento de aguas.

$\mathrm{m}^{3} / \mathrm{s}:$ metros cúbicos por segundo.

ii) los derechos no consuntivos, y su uso predominantemente hidroeléctrico, se concentran en el sur de Chile, donde existen condiciones ventajosas para la generación de este tipo de energía con respecto al norte.

Finalmente, una razón que podría explicar la recaudación de patentes cercana al $100 \%$ en derechos no consuntivos (véanse los cuadros 9,10 y 11) es el alto poder económico que tienen los propietarios de este tipo de derechos (principalmente compañías hidroeléctricas e inversionistas asociados a ellas), a diferencia de los derechos consuntivos en manos de propietarios pertenecientes a diversos rubros y con distintos niveles de capacidad financiera (véanse los cuadros 12 y 13). 
CUADRO 9

Total regional de patentes por no uso (PNU) cobradas y recaudadas, derechos no consuntivos, 2007

\begin{tabular}{|c|c|c|c|c|c|c|c|c|c|}
\hline \multirow{2}{*}{ Región } & \multicolumn{3}{|c|}{$\begin{array}{l}\text { Patentes } \\
\text { (en dólares) }\end{array}$} & \multicolumn{3}{|c|}{$\begin{array}{l}\text { Cantidad de derechos } \\
\text { (en unidades) }\end{array}$} & \multicolumn{3}{|c|}{$\begin{array}{l}\text { Caudal } \\
\left(\text { en } \mathrm{m}^{3} / \mathrm{s}\right)\end{array}$} \\
\hline & Cobradas & Recaudadas & Porcentaje & Afectos & Pagados & Porcentaje & Afecto & Pagado & Porcentaje \\
\hline Arica y Parinacota & - & - & - & - & - & - & - & - & - \\
\hline Tarapacá & - & - & - & - & - & - & - & - & - \\
\hline Antofagasta & - & - & - & - & - & - & - & - & - \\
\hline Atacama & - & - & - & - & - & - & - & - & - \\
\hline Coquimbo & 6064 & 6064 & 100,0 & 1 & 1 & 100,0 & 19000 & 19000 & 100,0 \\
\hline Valparaíso & 185813 & 185813 & 100,0 & 6 & 6 & 100,0 & 19525 & 19525 & 100,0 \\
\hline Metropolitana & 1324214 & 1317923 & 99,5 & 41 & 38 & 92,7 & 329632 & 326223 & 99,0 \\
\hline Macrozona norte-centro & 1516091 & 1509800 & 99,6 & 48 & 45 & 93,8 & 368157 & 364748 & 99,1 \\
\hline O’Higgins & 637869 & 522966 & 82,0 & 22 & 20 & 90,9 & 178766 & 126766 & 70,9 \\
\hline El Maule & 3328385 & 3295027 & 99,0 & 29 & 24 & 82,8 & 695142 & 675225 & 97,1 \\
\hline El Biobío & 223422 & 223422 & 100,0 & 14 & 14 & 100,0 & 262997 & 262997 & 100,0 \\
\hline La Araucanía & 687409 & 618827 & 90,0 & 56 & 48 & 85,7 & 481729 & 362929 & 75,3 \\
\hline Macrozona centro-sur & 4877084 & 4660241 & 95,6 & 121 & 106 & 87,6 & 1618634 & 1427918 & 88,2 \\
\hline Los Ríos & 2643369 & 2637565 & 99,8 & 85 & 83 & 97,6 & 1197965 & 1195969 & 99,8 \\
\hline Los Lagos & 4209094 & 4173071 & 99,1 & 67 & 55 & 82,1 & 1548904 & 1518253 & 98,0 \\
\hline Aysén & 116026 & 114771 & 98,9 & 8 & 6 & 75,0 & 219623 & 209064 & 95,2 \\
\hline Magallanes & 6861 & 5313 & 77,4 & 15 & 10 & 66,7 & 20754 & 16251 & 78,3 \\
\hline Macrozona sur-austral & 6975349 & 6930720 & 99,4 & 175 & 154 & 88,0 & 2987246 & 2939537 & 98,4 \\
\hline Total & 13368525 & 13100762 & 98,0 & 344 & 305 & 88,7 & 4974037 & 4732202 & 95,1 \\
\hline
\end{tabular}

Fuente: elaboración propia sobre la base de Dirección General de Aguas (DGA), Bases de datos del listado de derechos de aprovechamiento de aguas afectos a pago de patente por no uso, procesos 2007 a 2010, Santiago de Chile, Ministerio de Obras Públicas (MOP), 2010.

$m^{3} / s:$ metros cúbicos por segundo. 
CUADRO 10

Total regional de patentes por no uso (PNU) cobradas y recaudadas, derechos no consuntivos, 2008

\begin{tabular}{|c|c|c|c|c|c|c|c|c|c|}
\hline \multirow{2}{*}{ Región } & \multicolumn{3}{|c|}{$\begin{array}{l}\text { Patentes } \\
\text { (en dólares) }\end{array}$} & \multicolumn{3}{|c|}{$\begin{array}{l}\text { Cantidad de derechos } \\
\text { (en unidades) }\end{array}$} & \multicolumn{3}{|c|}{$\begin{array}{l}\text { Caudal } \\
\left(\text { en } \mathrm{m}^{3} / \mathrm{s}\right)\end{array}$} \\
\hline & Cobradas & Recaudadas & Porcentaje & Afectos & Pagados & Porcentaje & Afecto & Pagado & Porcentaje \\
\hline Arica y Parinacota & - & - & - & - & - & - & - & - & - \\
\hline Tarapacá & - & - & - & - & - & - & - & - & - \\
\hline Antofagasta & - & - & - & - & - & - & - & - & - \\
\hline Atacama & - & - & - & - & - & - & - & - & - \\
\hline Coquimbo & 6064 & 6064 & 100,0 & 1 & 1 & 100,0 & 19000 & 19000 & 100,0 \\
\hline Valparaíso & 186917 & 93252 & 49,9 & 7 & 6 & 85,7 & 19710 & 12710 & 64,5 \\
\hline Metropolitana & 2276787 & 2267453 & 99,6 & 50 & 45 & 90,0 & 458745 & 454507 & 99,1 \\
\hline Macrozona norte-centro & 2469768 & 2366769 & 95,8 & 58 & 52 & 89,7 & 497455 & 486216 & 97,7 \\
\hline O’Higgins & 1170448 & 1169585 & 99,9 & 38 & 37 & 97,4 & 281608 & 280906 & 99,8 \\
\hline El Maule & 3347907 & 3327924 & 99,4 & 32 & 26 & 81,3 & 699550 & 678134 & 96,9 \\
\hline El Biobío & 1455336 & 1041819 & 71,6 & 32 & 27 & 84,4 & 634520 & 500707 & 78,9 \\
\hline La Araucanía & 1145818 & 1049429 & 91,6 & 82 & 60 & 73,2 & 1157908 & 998526 & 86,2 \\
\hline Macrozona centro-sur & 7119510 & 6588757 & 92,5 & 184 & 150 & 81,5 & 2773587 & 2458272 & 88,6 \\
\hline Los Ríos & 2951593 & 2915768 & 98,8 & 125 & 103 & 82,4 & 1995057 & 1948879 & 97,7 \\
\hline Los Lagos & 4235675 & 4212171 & 99,4 & 104 & 77 & 74,0 & 1608296 & 1550983 & 96,4 \\
\hline Aysén & 122739 & 118909 & 96,9 & 9 & 6 & 66,7 & 223793 & 208515 & 93,2 \\
\hline Magallanes & 701 & 701 & 100,0 & 6 & 6 & 100,0 & 6171 & 6171 & 100,0 \\
\hline Macrozona sur-austral & 7310708 & 7247548 & 99,1 & 244 & 192 & 78,7 & 3833317 & 3714549 & 96,9 \\
\hline Total & 16899986 & 16203075 & 95,9 & 486 & 394 & 81,1 & 7104360 & 6659038 & 93,7 \\
\hline
\end{tabular}

Fuente: elaboración propia sobre la base de Dirección General de Aguas (DGA), Bases de datos del listado de derechos de aprovechamiento de aguas afectos a pago de patente por no uso, procesos 2007 a 2010, Santiago de Chile, Ministerio de Obras Públicas (MOP), 2010.

$m^{3} / s$ : metros cúbicos por segundo.

CUADRO 11

Total regional de patentes por no uso (PNU) cobradas y recaudadas, derechos no consuntivos, 2009

\begin{tabular}{|c|c|c|c|c|c|c|c|c|c|}
\hline \multirow{2}{*}{ Región } & \multicolumn{3}{|c|}{$\begin{array}{l}\text { Patentes } \\
\text { (en dólares) }\end{array}$} & \multicolumn{3}{|c|}{$\begin{array}{l}\text { Cantidad de derechos } \\
\quad \text { (en unidades) }\end{array}$} & \multicolumn{3}{|c|}{$\begin{array}{l}\text { Caudal } \\
\left(\text { en } \mathrm{m}^{3} / \mathrm{s}\right)\end{array}$} \\
\hline & Cobradas & Recaudadas & Porcentaje & Afectos & Pagados & Porcentaje & Afecto & Pagado & Porcentaje \\
\hline Arica y Parinacota & - & - & - & - & - & - & - & - & - \\
\hline Tarapacá & 1107 & - & - & 1 & - & - & 0150 & - & - \\
\hline Antofagasta & - & - & - & - & - & - & - & - & - \\
\hline Atacama & - & - & - & - & - & - & - & - & - \\
\hline Coquimbo & 6064 & 6064 & 100,0 & 1 & 1 & 100,0 & 19000 & 19000 & 100,0 \\
\hline Valparaíso & 100022 & 99967 & 99,9 & 5 & 4 & 80,0 & 7932 & 7710 & 97,2 \\
\hline Metropolitana & 2327341 & 2319171 & 99,6 & 55 & 51 & 92,7 & 467745 & 464447 & 99,3 \\
\hline Macrozona norte-centro & 2434534 & 2425203 & 99,6 & 62 & 56 & 90,3 & 494828 & 491156 & 99,3 \\
\hline O’Higgins & 1083655 & 1073045 & 99,0 & 37 & 35 & 94,6 & 279956 & 277268 & 99,0 \\
\hline El Maule & 3369928 & 3369069 & 100,0 & 31 & 29 & 93,5 & 700510 & 697010 & 99,5 \\
\hline El Biobío & 1740568 & 1519655 & 87,3 & 49 & 41 & 83,7 & 1273248 & 1132618 & 89,0 \\
\hline La Araucanía & 1610266 & 1181803 & 73,4 & 129 & 72 & 55,8 & 1433868 & 1061545 & 74,0 \\
\hline Macrozona centro-sur & 7804416 & 7143573 & 91,5 & 246 & 177 & 72,0 & 3687582 & 3168441 & 85,9 \\
\hline Los Ríos & 3026896 & 3005939 & 99,3 & 132 & 111 & 84,1 & 2007726 & 1947329 & 97,0 \\
\hline Los Lagos & 4293016 & 4229998 & 98,5 & 139 & 73 & 52,5 & 1609799 & 1508401 & 93,7 \\
\hline Aysén & 122834 & 121484 & 98,9 & 10 & 8 & 80,0 & 223793 & 213235 & 95,3 \\
\hline Magallanes & 389 & 306 & 78,8 & 2 & 1 & 50,0 & 3383 & 1870 & 55,3 \\
\hline Macrozona sur-austral & 7443134 & 7357727 & 98,9 & 283 & 193 & 68,2 & 3844702 & 3670836 & 95,5 \\
\hline Total & 17682085 & 16926502 & 95,7 & 591 & 426 & 72,1 & 8027112 & 7330434 & 91,3 \\
\hline
\end{tabular}

Fuente: elaboración propia sobre la base de Dirección General de Aguas (DGA), Bases de datos del listado de derechos de aprovechamiento de aguas afectos a pago de patente por no uso, procesos 2007 a 2010, Santiago de Chile, Ministerio de Obras Públicas (MOP), 2010.

$m^{3} / s$ : metros cúbicos por segundo. 
CUADRO 12

Propietarios de daa afectos a mayores cobros de patente por no uso (PNU), 2010

\begin{tabular}{|c|c|c|c|c|c|}
\hline Clasificación & Propietario & Rubro & $\begin{array}{c}\text { Patentes } \\
\text { (en dólares) }\end{array}$ & $\begin{array}{l}\text { Cantidad de derechos } \\
\text { (en unidades) }\end{array}$ & $\begin{array}{l}\text { Caudal } \\
\left(\text { en } \mathrm{m}^{3} / \mathrm{s}\right)\end{array}$ \\
\hline 1 & ENDESA S. A. & Hidroelectricidad & 6478281 & 17 & 157505 \\
\hline 2 & AEs Gener S. A. & Hidroelectricidad & 3549024 & 58 & 115632 \\
\hline 3 & Colbún S. A. & Hidroelectricidad & 1771140 & 22 & 151402 \\
\hline 4 & CGE Generación S. A. & Hidroelectricidad & 1183343 & 16 & 49553 \\
\hline 5 & Hidroeléctrica Trayenko S. A. & Hidroelectricidad & 1085390 & 46 & 25952 \\
\hline 6 & Inversiones Arlequín Ltda. & Inversiones & 549584 & 11 & 1351 \\
\hline 7 & CODELCO & Minería & 378603 & 22 & 755 \\
\hline 8 & Hidroeléctrica La Higuera S. A. & Hidroelectricidad & 286177 & 13 & 6560 \\
\hline 9 & Exploraciones, Inversiones y Asesorías Huturi S. A. & Inversiones & 274127 & 29 & 12019 \\
\hline 10 & Hidroeléctrica La Confluencia. S. A. & Hidroelectricidad & 233485 & 8 & 5920 \\
\hline 11 & Exploraciones, Inversiones y Asesorías Mundo S. A. & Inversiones & 121658 & 15 & 102 \\
\hline 12 & Forestal Valdivia S. A. & Forestal & 118157 & 10 & 1475 \\
\hline 13 & Álvaro Flaño García & Persona natural & 77252 & 10 & 6612 \\
\hline 14 & Maderera Panguipulli S. A. & Forestal & 49119 & 12 & 5041 \\
\hline 15 & Eléctrica Panguipulli S. A. & Hidroelectricidad & 38565 & 11 & 9485 \\
\hline \multirow{2}{*}{\multicolumn{3}{|c|}{$\begin{array}{l}\text { Total } \\
\text { Proporción del total }\end{array}$}} & 16193906 & 300 & 549366 \\
\hline & & & $520 \%$ & $100 \%$ & $516 \%$ \\
\hline
\end{tabular}

Fuente: elaboración propia sobre la base de Dirección General de Aguas (DGA), Bases de datos del listado de derechos de aprovechamiento de aguas afectos a pago de patente por no uso, procesos 2007 a 2010, Santiago de Chile, Ministerio de Obras Públicas (MOP), 2010.

DAA: derechos de aprovechamiento de aguas.

$m^{3} / s$ : metros cúbicos por segundo.

CUADRO 13

Total por rubro de patentes por no uso (PNU) cobradas, 2010

\begin{tabular}{|c|c|c|c|c|c|c|}
\hline Rubro & $\begin{array}{l}\text { Patentes } \\
\text { (en dólares) }\end{array}$ & Porcentaje & $\begin{array}{l}\text { Cantidad de derechos } \\
\quad \text { (en unidades) }\end{array}$ & Porcentaje & $\begin{array}{l}\text { Caudal } \\
\left(\text { en } \mathrm{m}^{3} / \mathrm{s}\right)\end{array}$ & Porcentaje \\
\hline Personas naturales & 4068945 & 13,1 & 1329 & 44,3 & 1345,3 & 12,6 \\
\hline Agrícultura & 1583207 & 5,1 & 376 & 12,5 & 904,6 & 8,5 \\
\hline Pesca y acuicultura & 78534 & 0,3 & 90 & 3,0 & 157,3 & 1,5 \\
\hline Minería & 897647 & 2,9 & 163 & 5,4 & 15,3 & 0,1 \\
\hline Forestal & 561805 & 1,8 & 78 & 2,6 & 239,3 & 2,2 \\
\hline Hidroelectricidad & 18187182 & 58,4 & 279 & 9,3 & 7544,7 & 70,9 \\
\hline Servicios sanitarios & 712931 & 2,3 & 98 & 3,3 & 14,8 & 0,1 \\
\hline Inmobiliaria & 319953 & 1,0 & 83 & 2,8 & 19,5 & 0,2 \\
\hline Asociaciones civiles & 60870 & 0,2 & 40 & 1,3 & 6,5 & 0,1 \\
\hline Otras personas jurídicas & 4650271 & 14,9 & 466 & 15,5 & 396,2 & 3,7 \\
\hline Total & 31121345 & 100,0 & 3002 & 100,0 & 10643,5 & 100,0 \\
\hline
\end{tabular}

Fuente: elaboración propia sobre la base de Dirección General de Aguas (DGA), Bases de datos del listado de derechos de aprovechamiento de aguas afectos a pago de patente por no uso, procesos 2007 a 2010, Santiago de Chile, Ministerio de Obras Públicas (MOP), 2010.

$m^{3} / s:$ metros cúbicos por segundo. 


\section{Precio de mercado de derechos con respecto al cobro de la PNU}

En los derechos consuntivos, la estimación de precios promedio de mercado arroja resultados muy variados en las distintas regiones. Al comparar estas cifras con una PNU diferenciada en tres macrozonas de aplicación, se producen disparidades en los años de pago de patente que serían necesarios para superar el precio promedio de mercado de los derechos. Mientras que en las regiones de Arica y Parinacota, Coquimbo, Valparaíso, Metropolitana, Los Lagos y Magallanes, los años necesarios de pago acumulado de patente para superar el precio promedio de mercado van entre 18 y 22, en Antofagasta y Atacama este plazo es aproximadamente de 100 años (véase el cuadro 14). Esta situación se ve finalmente reflejada en diferencias de disposición a pagar, dado que la PNU será una carga menor para un propietario al que se le cobra una patente que representa una fracción mínima del precio que su derecho podría alcanzar en el mercado, y una carga mayor para quien tenga que pagar una patente que constituye un porcentaje importante del precio de su derecho, situación que se puede observar contrastando los porcentajes de pago de los cuadros 6,7 y 8 con los datos del cuadro 14.

En derechos no consuntivos se obtuvieron datos de tan solo ocho transacciones que permitían calcular la patente equivalente. Si bien las diferencias de precio son considerables, resulta complejo comparar por este campo, ya que los derechos transados son distintos en varios aspectos como caudal, ejercicio y desnivel. No obstante, los años de pago de patente necesarios para superar el precio de transacción permiten contrastar las diferencias (véase el cuadro 15). De todos modos, al tener precios de mercado puntuales y no promedio como se hizo con los derechos consuntivos, se hace difícil evaluar por el criterio $\mathrm{C}$ si la patente para derechos no consuntivos es o no adecuada para desincentivar el no uso. Sin embargo, los precios que alcanzarían en el mercado algunos derechos de este tipo harían necesarios más de dos siglos de pago de patente para igualarlos, lo que vendría a apoyar la idea de que el diseño de la PNU ha sido laxo con respecto a los derechos no consuntivos.

CUADRO 14

Precio estimado de mercado y cobro acumulado

de PNU regional para derecho consuntivo, permanente y continuo de $50 \mathrm{l} / \mathrm{s}$

\begin{tabular}{|c|c|c|c|c|c|c|c|c|c|c|}
\hline \multirow{2}{*}{ Región } & \multirow{2}{*}{$\begin{array}{l}\text { Precio promedio } \\
\text { estimado de } \\
\text { mercado } \\
\text { (en dólares) }\end{array}$} & \multicolumn{8}{|c|}{$\begin{array}{l}\text { Patente acumulada } \\
\text { (en dólares) }\end{array}$} & \multirow{2}{*}{$\begin{array}{l}\text { Años de pago } \\
\text { de patente para } \\
\text { superar precio }\end{array}$} \\
\hline & & Año 1 & Porcentaje & Año 5 & Porcentaje & Año 10 & Porcentaje & Año 15 & Porcentaje & \\
\hline Arica y Parinacota & 262177 & 5952 & 2,3 & 29760 & 11,4 & 89280 & 34,1 & 208319 & 79,5 & 18 \\
\hline Tarapacá & 1472769 & 5952 & 0,4 & 29760 & 2,0 & 89280 & 6,1 & 208319 & 14,1 & 69 \\
\hline Antofagasta & 2182564 & 5952 & 0,3 & 29760 & 1,4 & 89280 & 4,1 & 208319 & 9,5 & 98 \\
\hline Atacama & 2481823 & 5952 & 0,2 & 29760 & 1,2 & 89280 & 3,6 & 208319 & 8,4 & 111 \\
\hline Coquimbo & 337036 & 5952 & 1,8 & 29760 & 8,8 & 89280 & 26,5 & 208319 & 61,8 & 21 \\
\hline Valparaíso & 307981 & 5952 & 1,9 & 29760 & 9,7 & 89280 & 29,0 & 208319 & 67,6 & 20 \\
\hline Metropolitana & 274622 & 5952 & 2,2 & 29760 & 10,8 & 89280 & 32,5 & 208319 & 75,9 & 18 \\
\hline O’Higgins & 145904 & 744 & 0,5 & 3720 & 2,5 & 11160 & 7,6 & 26040 & 17,8 & 56 \\
\hline El Maule & 115638 & 744 & 0,6 & 3720 & 3,2 & 11160 & 9,7 & 26040 & 22,5 & 46 \\
\hline El Biobío & 85880 & 744 & 0,9 & 3720 & 4,3 & 11160 & 13,0 & 26040 & 30,3 & 36 \\
\hline La Araucanía & 50095 & 744 & 1,5 & 3720 & 7,4 & 11160 & 22,3 & 26040 & 52,0 & 24 \\
\hline Los Ríos & 43091 & 372 & 0,9 & 1860 & 4,3 & 5580 & 12,9 & 13020 & 30,2 & 36 \\
\hline Los Lagos & 22485 & 372 & 1,7 & 1860 & 8,3 & 5580 & 24,8 & 13020 & 57,9 & 22 \\
\hline Aysén & 54264 & 372 & 0,7 & 1860 & 3,4 & 5580 & 10,3 & 13020 & 24,0 & 43 \\
\hline Magallanes & 19182 & 372 & 1,9 & 1860 & 9,7 & 5580 & 29,1 & 13020 & 67,9 & 20 \\
\hline
\end{tabular}

Fuente: elaboración propia sobre la base de Dirección General de Aguas, Base de datos de transacciones de derechos de aprovechamiento a diciembre de 2009 informadas por los Conservadores de Bienes Raíces, Santiago de Chile, Ministerio de Obras Públicas (MOP), 2009 [en línea] http://www.dga.cl/administracionrecursoshidricos/cbr/Documents/2registrosmodificadoscbr.xls y Listado de remates de derechos de aprovechamiento de aguas realizados para situaciones en que dos o más solicitudes se contraponen, Santiago de Chile, Ministerio de Obras Públicas, 2010; José Pedro Gallo, Listado de remates de derechos de aprovechamiento de aguas realizados, Santiago de Chile, Remates Fernando Zañartu Rozas y Cía. Ltda., 2010; y Ministerio de Obras Públicas (MOP), Ley No 20.017: Modifica el Código de Aguas, Santiago de Chile, 2005 [en línea] http://www.leychile.cl/Navegar?idNorma=239221 


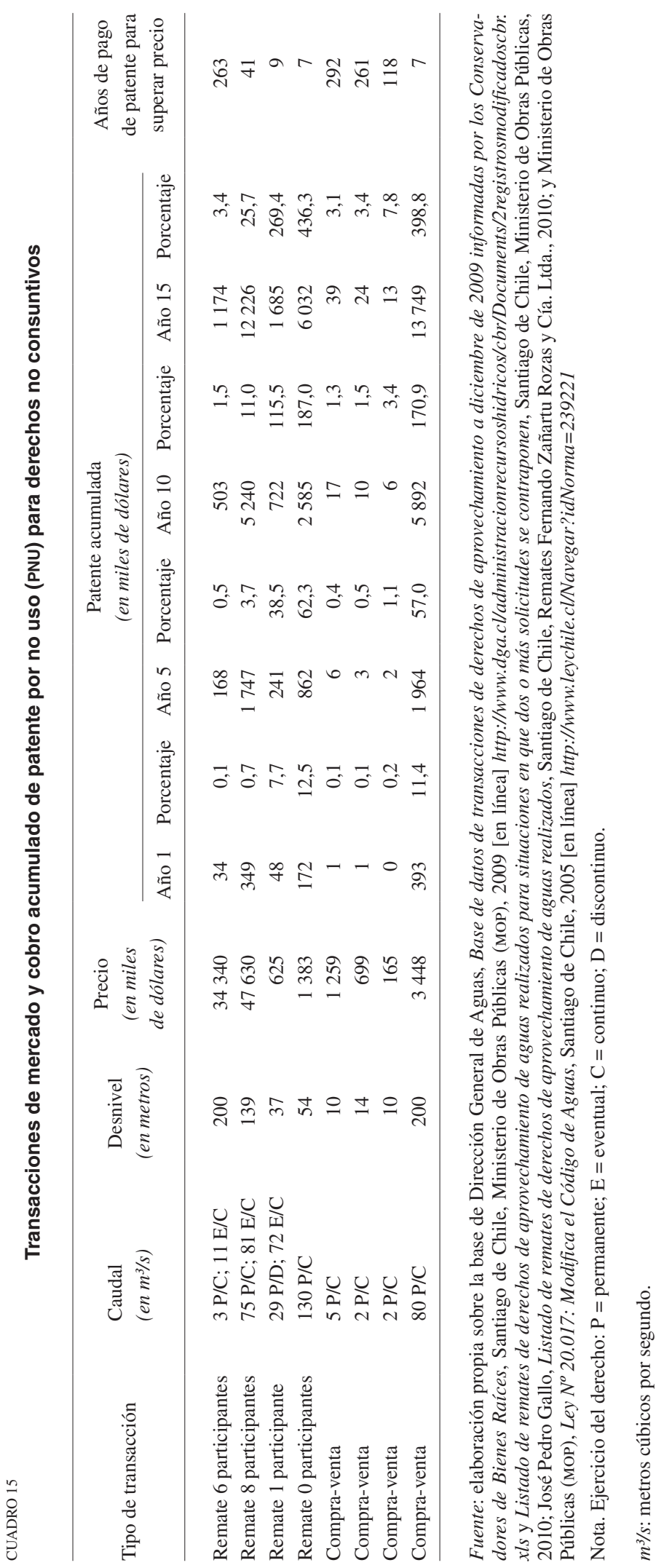


Como se desprende de la Introducción, el objetivo de la PNU no es recaudatorio, sino que las aguas efectivamente se utilicen, esto significa que en Chile el Estado prefiere que los propietarios de DAA no utilizados en lugar de pagar la patente por no uso tomen uno de estos cinco caminos: no pagar la patente y perder el derecho en un remate público, renunciar, vender, arrendar o utilizar efectivamente (o, en estricto rigor, construir las obras de captación y restitución según corresponda). Es razonable pensar que a medida que pase el tiempo un propietario de un DAA no utilizado esté cada vez menos dispuesto a pagar la patente respecto del año anterior. Dicho esto, un elemento que aporta al análisis es conocer aquellos primeros años del proceso de cobro de la patente en los que un propietario debiera estar más dispuesto a tomar uno de los cinco caminos descritos para salir del listado. Según como está diseñada la PNU, estos debieran ser:

i) el primer año, debido a que el propietario podría simplemente no estar dispuesto a pagar patente;

ii) el sexto, ya que es el primer año en que el valor de la patente se duplica, acrecentando las posibilidades de que un propietario de un derecho no utilizado no esté dispuesto a pagar. Además, respecto de DAA consuntivos, de construirse las obras de captación en este año se recupera todo lo pagado en patentes, lo que no sucedería en el séptimo, octavo y siguientes años, en que de construirse dichas obras se perdería definitivamente la patente pagada durante los años primero, segundo y siguientes, respectivamente, debido a que para este tipo de derechos y una vez construidas las obras se devuelve solo lo pagado en los últimos cinco años;

iii) el noveno año, en derechos no consuntivos, ya que para este tipo de derechos y una vez construidas las obras de captación y restitución se devuelve solo lo pagado en los últimos ocho años; y

iv) el año undécimo, dado que es la primera vez en que la patente se cuadruplica con respecto al primer año de cobro, incrementando nuevamente las posibilidades de que un propietario de un DAA no utilizado no esté dispuesto a pagar.

Si bien los años descritos marcan hitos en el proceso de cobro, que aumentan el incentivo a la utilización efectiva del agua que promueve la PNU, se observa que la cantidad de años de pago necesarios para superar el precio promedio de mercado en los derechos consuntivos (véase el cuadro 14) es superior a 11 (último año con hito respecto del proceso de cobro) en todas las regiones - aunque con notables diferencias-, por lo que se podría estimar que la patente no desincentivará la posesión de derechos consuntivos no utilizados en el corto plazo. Sin embargo, y como se comentó anteriormente, han salido del listado algunos DAA de gran importancia, razón que hace pensar que la patente podría mejorar su desempeño en el corto plazo respecto de este tipo de derechos.

En contraste, en los DAA no consuntivos hay casos en que la cantidad de años de pago de patente para superar el precio de transacción es menor que 11, pero también hay otros en que se supera varias veces esa cantidad, incluso sumando siglos de pago para sobrepasar el precio de transacción (véase el cuadro 15). A la luz de las primeras tendencias observadas en cuanto a recaudación de patentes, estos últimos casos permiten afirmar que la PNU no cumplirá su objetivo en el corto plazo respecto de este tipo de derechos.

\section{Mecanismos de evasión de la patente}

El origen de los mecanismos de evasión de la patente está en el mismo diseño de la PNU y en el Código de Aguas original de 1981, que no permite que la tarea de favorecer el uso efectivo y beneficioso sea una corrección sencilla de implementar a través de una patente por no uso, que en realidad es una patente por no obras. Estos mecanismos son principalmente dos: la no inscripción de DAA en el Conservador de Bienes Raíces y la construcción de obras sin uso efectivo.

\section{a) No inscripción de DAA en el Conservador de Bienes Raíces (CBR)}

Existen casos en que no se ha podido ejecutar el remate por no pago de la patente debido a que muchos derechos no están debidamente inscritos en el CBR, lo que impide, de acuerdo con la ley, realizar el remate (Vásquez, 2010). Se estima que los DAA no inscritos en el Conservador y afectos a la PNU ascienden a alrededor de 1.000 , cantidad que representaba cerca del $30 \%$ de los derechos afectos a la patente por no uso en 2010 (Riestra, 2010). La imposibilidad de rematar una parte importante de los DAA es un obstáculo que pone en jaque los objetivos que se establecieron con la patente, porque si bien en el Código se señala la obligatoriedad de la inscripción en el CBR, no se establecen sanciones para el incumplimiento de este acto (Riestra, 2009b) y además se reconoce la existencia de derechos no inscritos tanto en su artículo 181, como en su artículo $2^{\circ}$ transitorio. Esta situación no resuelta ha originado que algunos especialistas sugirieran que deba haber una garantía al derecho de propiedad, mediante un proceso administrativo de caducidad, extinción o de término 
del derecho en caso de que no se inscriba en el CBR (Schulbach, 2010).

Extrañamente, los derechos que no se pueden rematar por no estar inscritos en el CBR han paralizado en algunas ocasiones el remate de derechos que sí están inscritos, dado que algunos jueces prefieren rematar todo el listado de derechos de una sola vez (Riestra, 2009b).

\section{b) Construcción de obras sin uso efectivo}

La autoridad estatal de agua conoce de casos en que se han construido obras de captación de agua, para derechos consuntivos, con el solo propósito de no pagar la patente, sin que exista un uso efectivo y beneficioso, situación similar a lo predicho por algunos autores antes de la aprobación de la reforma de 2005 al Código de Aguas de 1981 (Paredes y Gómez-Lobo, 2000; Domper, 2003).

Resulta fácil habilitar obras para simular la extracción de aguas subterráneas, ya que los propietarios de derechos instalan motores diésel para justificar ante los fiscalizadores la falta de electricidad en el momento de la inspección, pero que sí están usando las aguas, cuando en realidad son instalaciones ficticias destinadas a eludir el pago de la patente (Proschle, 2010).

\section{IV}

\section{Conclusiones}

Luego del análisis de los resultados de la aplicación de la PNU en sus cuatro primeros años se concluye que el desincentivo para poseer DAA sin uso efectivo aún no es eficaz, por varias razones. Una de ellas es que todos los procesos de cobro de patente han registrado pagos superiores al $67 \%$ y en ascenso. No obstante, esto podría cambiar si es que los propietarios comienzan a utilizar efectivamente sus derechos, devolviéndoseles las patentes pagadas y, en consecuencia, acercándose a una recaudación "cero". Además, la eliminación del acaparamiento y la especulación se percibe como débil en una primera etapa, por cuanto se observa que son necesarios varios años de pago de PNU para superar los precios de mercado de los DAA, razón que permite suponer que dicha patente seguirá registrando altos porcentajes de pago en el corto plazo.

Otra razón es que, en la práctica, la disponibilidad de las aguas está cautelándose en beneficio de quienes tienen poder económico suficiente para pagar patente
En cuanto a las aguas superficiales, Riestra (2010) señala que se han detectado casos en que la bocatoma no conduce a ninguna parte y como eran obras aprobadas por la DGA no se les pudo cobrar patente en los primeros dos años (2007 y 2008). Existe, sin embargo, un dictamen de la Corte Suprema (2010) para estas situaciones en aguas superficiales, pero el proceso de re-revisión es por ahora lento.

Las simulaciones descritas no se han detectado en derechos no consuntivos ya que, tal como predijeron Jara y Melo (2003), es improbable que se construyan obras superfluas para emular el ejercicio de este tipo de DAA, por cuanto están sometidas al papel regulador del Estado en el caso de instalaciones hidroeléctricas. Por lo demás, las obras de captación y restitución necesarias para ejercer derechos no consuntivos son, generalmente, muy superiores en costo a las obras de captación para ejercer DAA consuntivos.

Finalmente, el funcionamiento de este mecanismo de evasión de la patente, prácticamente exclusivo de derechos consuntivos, puede ser una de las razones que explican la mayor cantidad de salidas del listado de cobro de este tipo de derechos con respecto a derechos no consuntivos.

y no precisamente de quienes necesitan las aguas y contemplan proyectos de uso efectivo y beneficioso. Esto significa que en la competencia por el uso del agua se está favoreciendo a quienes están en condiciones de retrasar sus inversiones pagando patente por no uso, es decir, a un subconjunto del universo de usuarios potenciales del agua.

En cuanto a las renuncias, si bien las hay, son pocas en cantidad (22) en relación con el total de DAA del listado y solo tres son importantes en cuanto a las patentes que representan. Las escasas renuncias pueden obedecer a que, ante el cobro, un propietario estaría dispuesto en teoría a aceptar cualquier precio que esté por sobre la PNU antes que desistir de su derecho, e incluso jamás le convendría renunciar, dado que siempre sería preferible esperar el remate de su derecho de aprovechamiento de aguas y luego recibir los excedentes del precio de adjudicación.

En cuanto a los derechos consuntivos, la patente presenta importantes diferencias territoriales. En este 
sentido, las constantes que se establecieron para diferenciar la patente por macrozonas del país están resultando poco sensibles a las realidades locales, colocando en una misma condición a cuencas distintas en condiciones hidrológicas y vocaciones de uso, lo que está derivando en comportamientos diferenciados por latitud entre los propietarios y, como consecuencia de ello, en mejores resultados de la patente dentro de una misma macrozona en aquellas regiones donde los DAA son más baratos (o donde existe mayor disponibilidad de recursos hídricos).

Por otra parte, en los derechos no consuntivos el cobro es mucho menos severo que en el caso de los consuntivos. Lo anterior se demuestra porque los porcentajes de pago de la patente en DAA no consuntivos han superado el $95 \%$ en todos los procesos. Además, existe evidencia empírica que demuestra que los derechos de este tipo se están moviendo en dirección a las compañías hidroeléctricas, que pagan la patente sin dificultades financieras. Si bien se podría pensar que los DAA sin uso que aún subsisten están en esa condición porque son valorados por sus respectivos dueños y pronto se pondrán en uso, también es posible inferir, sobre todo en derechos no consuntivos, que para algunos grupos es conveniente mantener sin uso esos derechos a fin de impedir la entrada de nuevos actores a sus mercados y mantener oligopolios.

Lo anterior sugiere que es probable que la eficiencia de la PNU mejore con el tiempo en el caso de los derechos consuntivos, puesto que se ha observado que sus patentes son pagadas con mayor dificultad que en el caso de los derechos no consuntivos.

La pretensión de favorecer el uso racional de los recursos hídricos se está encontrando con el temor de los propietarios a perder sus DAA, aprensión que en algunos casos se traduce en la construcción de obras solo para evitar la patente, ambigüedad que podría solucionarse con dictámenes del poder judicial. Sobre la no inscripción de los DAA en el CBR, la conclusión es que su gravedad amerita modificaciones legales al Código de Aguas.

Es llamativo el camino del "cobro por no uso del agua" que se adoptó en Chile, un enfoque de abundancia de los recursos hídricos en un contexto internacional donde predomina el enfoque de escasez a través del "cobro por uso (o tenencia) del agua". En este sentido, al ser inusual el camino escogido, cobra mayor importancia la evaluación ex post de la legislación, pues de lo contrario, y al no existir experiencias internacionales para comparar, las futuras modificaciones a la ley solo se justificarán una vez que se consumen sus eventuales efectos no deseados.
Es pertinente el cuestionamiento acerca de cuál hubiera sido una mejor alternativa, políticamente factible, al cobro por no uso. El requerimiento de uso efectivo y beneficioso, un criterio universal en la dictación de normas de agua, era una mejor opción que la PNU; sin embargo, la única solución directa para aplicarlo en Chile es la caducidad de aquellos DAA sin uso, medida que no fue políticamente factible. El cobro por el uso o tenencia del agua no es exactamente una alternativa a la patente por no uso, sino más bien un instrumento compatible y complementario a ella; además, es una iniciativa a largo plazo y de muy compleja definición y que no responde al objetivo central que se está tratando de resolver con la PNU (Comisión de Hacienda del Senado, 2000; Comisión de Obras Públicas del Senado, 2004, citados por Valenzuela, 2009). Perfeccionar la legislación de aguas resulta conflictivo y limitado al reducido espacio de acción que tienen las políticas públicas para desarrollarse. Esto se debería a que los recursos hídricos están envueltos en conflictos de intereses, siendo las pugnas entre los distintos actores muchas veces un "diálogo entre sordos" que impide alcanzar consensos. Asimismo, entre otras razones, lo que algunos consideran como un error en la legislación, para otros es fuente de oportunidades. Bajo esa lógica, el establecimiento de la PNU es una respuesta imaginativa a un problema que tenía difícil salida (Valenzuela, 2009).

i) Una alternativa más evidente políticamente factible es perfeccionar la ya establecida PNU. Su diseño puede mejorar en cuanto dicha patente se aplique a cuencas y acuíferos en lugar de regiones políticoadministrativas, previniendo así que situaciones de cambio de punto de captación o traslado de DAA de una región a otra - esto es, cuando la fuente de agua cruza el límite y está en dos regiones a la vez - terminen en patentes menores a las cobradas inicialmente.

ii) Que el valor de las constantes macrozonales para calcular las patentes se determine sobre la base del precio de mercado de los DAA, dado que en las metodologías originalmente utilizadas se incluía información de solo un sector productivo por tipo de derecho de aprovechamiento de aguas, es decir, empresas de servicios sanitarios para derechos consuntivos (Peña, 1999 citado por Valenzuela, 2009) e hidroeléctricas para no consuntivos (CNE, 1997, citado por Valenzuela, 2009), lo que sesgó el análisis y la posterior determinación de los montos a cobrar.

iii) Que la progresividad de la PNU para los derechos no consuntivos se aplique como se planteó inicialmente 
en la discusión parlamentaria, esto es, multiplicando la patente por 5 en los años sexto a décimo, y por 25 desde el año undécimo en adelante, pues se ha observado poca efectividad de la medida en este tipo de derechos.

iv) Que los valores de los caudales de exención se apliquen como descuento a los caudales no exentos. En efecto, con el sistema actual se da que, por ejemplo, un derecho consuntivo, permanente y continuo de 10,1 1/s en la macrozona norte-centro está afecto a PNU, mientras que un derecho de las mismas características, pero por un caudal de 9,9 1/s, está exento.

v) Que en la ecuación de cálculo se incluya un monto universal que cubra los costos administrativos que tiene para el Estado ejecutar la PNU, dado que la inclusión de algunos derechos en los listados significa altos costos para el aparato público en relación con su importancia para el desarrollo económico.

vi) Que cualquier DAA perteneciente a una entidad estatal, sea cual sea, esté exento del pago de patente $\mathrm{y}$, en el evento de que sea transferido a un privado, se hagan efectivas las deudas de patentes - a cargo de la entidad estatal - de todos los años en que el derecho haya estado sin uso. Así se previene que el Estado se cobre patente a sí mismo cuando sus derechos tienen fines estratégicos y no existe intención de transferirlos, como en los casos de derechos pertenecientes al Ejército de Chile (fines militares) y la Municipalidad de Pucón (fines de conservación para el fomento de la actividad turística). Si bien en el Código de Aguas se previenen estas situaciones por medio de caudales de reserva y caudales ecológicos, estos están supeditados a no afectar los derechos de terceros y deben pasar necesariamente por el Presidente de la República; en el caso de los caudales ecológicos, estos están limitados a una cantidad determinada.

vii) Que esté exento del pago de patente cualquier derecho que tenga prohibición de enajenación, y por ende de ser objeto de especulación, como por ejemplo aquellos adquiridos a nombre de comunidades indígenas a través del Fondo de Tierra y Aguas Indígenas de la Corporación Nacional de
Desarrollo Indígena (CONADI). Ello en virtud de que si estas patentes se cobran y luego no se pagan, igualmente los DAA asociados a ellas no podrán ser rematados ni redistribuidos, lo que permite argüir que todo el gasto vinculado a los trámites constituye un sinsentido.

viii) Que aquellos derechos afectos a la patente por no uso y que no registren su inscripción conservatoria en el Catastro Público de Aguas que lleva la DGA, sean extinguidos en un plazo determinado contado desde la notificación de esta medida. Con esto se previene la evasión de la PNU. Asimismo, y yendo más allá de la patente, sería conveniente que cualquier DAA sin inscripción conservatoria en dicho catastro esté afecto a una multa si no se cumple con el trámite de inscripción en un plazo determinado; así se previene un problema común en el Catastro Público de Aguas, que suele estar desactualizado con respecto a la realidad de los DAA.

Finalmente, es relevante comentar si la PNU ha implicado una mayor presión sobre los recursos hídricos. Esta afirmación es cierta en teoría, dado que dicha patente es promotora del uso del agua, lo que en zonas de mayor escasez de este elemento puede resultar complejo, en circunstancias que las medidas debieran apuntar a la disminución de las extracciones. Sin embargo, en la práctica, hasta ahora ha ocurrido que en los acuíferos con mayor escasez de recursos hídricos las patentes se han pagado mayoritariamente, por lo tanto, la presión que estaría implicando la PNU aún no se manifiesta explícitamente, aunque esto podría cambiar con el paso del tiempo y el aumento de la progresividad. En el mejor de los casos, las organizaciones de usuarios de aguas de los acuíferos con mayor escasez de recursos hídricos (muchas de las cuales aún no se constituyen), realizarán las gestiones necesarias para acogerse a dos exenciones al pago de la patente especialmente diseñadas para este tipo de situaciones: sujeción a turno o reparto proporcional de los DAA y no existencia de hechos, actos o convenciones que impidan, restrinjan o entorpezcan la libre competencia en su área; situaciones que necesariamente dependerán del apoyo y la capacidad de gestión que estas organizaciones adquieran. 
Aylwin, Patricio (1992), "Mensaje de S.E. el Presidente de la República con el que inicia un proyecto de Ley que modifica el Código de Aguas", Mensaje, № 283-325, Santiago de Chile [en línea] http://sil.congreso.cl/cgi-bin/sil_abredocumentos.pl?1,308

Barde, Jean Philippe y Nils Axel Braathen (2002), "Diseño y efectividad de los instrumentos fiscales relacionados con el medio ambiente en los países de la OCDE", Gaceta Ecológica, № 63, México, D.F. [en línea] http://redalyc.uaemex.mx/redalyc/ pdf/539/53906304.pdf

CEPAL (Comisión Económica para América Latina y el Caribe) (1995), "Mercados de derechos de agua: Entorno legal" (LC/R.1485), Santiago de Chile [en línea] http://www.eclac.org/publicaciones/ $\mathrm{xml} / 0 / 5670 / \mathrm{Lcr} 1485$ e.pdf

CNE (Comisión Nacional de Energía) (1997), "Informe de la Comisión Especial Legislativa encargada del estudio del régimen jurídico de las aguas sobre el proyecto de ley que modifica el Código de Aguas", Boletín, No 876-09, Valparaíso, Chile, 18 de marzo, [en línea] http://sil.congreso.cl

Comisión de Hacienda del Senado (2004), "Segundo informe de la Comisión de Hacienda, recaído en el proyecto de ley, en segundo trámite constitucional, que modifica el Código de Aguas", Boletín, No 876-09, Valparaíso, Chile, Congreso Nacional [en línea] http://sil.congreso.cl/cgi-bin/sil_abredocumentos.pl?2,7105 (2000), "Informe de la Comisión de Hacienda, recaído en el proyecto de ley de la $\mathrm{H}$. Cámara de Diputados que modifica el Código de Aguas", Boletín, № 876-09, Valparaíso, Chile, 15 de septiembre [en línea] http://sil.congreso.cl

Comisión de Obras Públicas del Senado (2004), "Segundo informe de la Comisión de Hacienda, recaído en el proyecto de Ley, en segundo trámite constitucional, que modifica el Código de Aguas", Boletín, No 876-09, Valparaíso, Chile, Congreso Nacional [en línea] http://sil.congreso.cl/cgi-bin/sil abredocumentos.pl?2,7105

Comisión Especial sobre Régimen Jurídico de las Aguas (1997), "Informe de la Comisión Especial Legislativa encargada del estudio del régimen jurídico de las aguas sobre el proyecto de Ley que modifica el Código de Aguas", Boletín, No 876-09, Valparaíso, Chile, Congreso Nacional [en línea] http://sil. congreso.cl/cgi-bin/sil_abredocumentos.pl?2,8792

Comisión Preventiva Central (1996), "Dictamen de la Comisión ante consulta del Sr. Ministro Presidente de la Comisión Nacional de Energía", C.P.C. No 992/636, Santiago de Chile, Fiscalía Nacional Económica [en línea] http://mailweb.fne.gob.cl/db/ jurispru.nsf/916bbd5360412187842573\%203e005e4291/2b2 8b1f6d94c0fb408256e1c000a27de/\$FILE/Doc0047.pdf

Corte Suprema (2010), "Pronunciamiento en autos caratulados "Hidroeléctrica Guardia Vieja S.A. con Dirección General de Aguas", Rol de Corte, N ${ }^{\circ}$ 5083-2008, Santiago de Chile, Poder Judicial.

DGA (Dirección General de Aguas) (2010a), Bases de datos del listado de derechos de aprovechamiento de aguas afectos a pago de patente por no uso, procesos 2007 a 2010, Santiago de Chile, Ministerio de Obras Públicas.

(2010b), Listado de remates de derechos de aprovechamiento de aguas realizados para situaciones en que dos o más solicitudes se contraponen, Santiago de Chile, Ministerio de Obras Públicas.

(2010c), Informe sobre patente por no uso de derechos de aprovechamiento de aguas, Santiago de Chile, Ministerio de Obras Públicas.

(2010d), Informe de la elaboración del listado de derechos de aprovechamiento de aguas afectos a pago de patente por no uso, proceso 2010, Santiago de Chile, Ministerio de Obras Públicas.

(2009), Base de datos de transacciones de derechos de aprovechamiento a diciembre de 2009 informadas por los Conservadores de Bienes Raíces, Santiago de Chile, Ministerio de Obras Públicas [en línea] http://www.dga.cl/ administracionrecursoshidricos/cbr/Documents/2registrosmo dificadoscbr.xls

Domper, María de la Luz (2003), "La eficiencia en el mercado de derechos de agua: ¿Patente por no-uso o por tenencia?”, Serie Informe Económico, $\mathrm{N}^{\circ}$ 141, Santiago de Chile, Instituto Libertad y Desarrollo [en línea] http://www.libertadydesarrollo.cl/ biblioteca/serie/Economico/141_serie_informe_economico.pdf

Dourojeanni, Axel y Andrei Jouravlev (1999), "El Código de Aguas de Chile: Entre la ideología y la realidad", serie Recursos naturales e infraestructura, $\mathrm{N}^{\circ} 3$ (LC/L.1263-P), Santiago de Chile, Comisión Económica para América Latina y el Caribe (CEPAL). Publicación de las Naciones Unidas, $\mathrm{N}^{\mathrm{o}}$ de venta: S.99.II.G.43 [en línea] http://www.eclac.org/publicaciones/ xm1/5/4465/lc11263.pdf

Gallo, José Pedro (2010), Listado de remates de derechos de aprovechamiento de aguas realizados, Santiago de Chile, Remates Fernando Zañartu Rozas y Cia. Ltda.

Jara, Esteban y Oscar Melo (2003), "Patentes de no uso de derechos de aprovechamiento en la reforma al Código de Aguas: ¿Se justifica su implementación?", VIII Congreso de Economistas Agrarios. Pensando la agricultura del 2010: Desafíos, ajustes y política, Santiago de Chile, Pontificia Universidad Católica de Chile [en línea] http://www.aeachile.cl/docs/congresos/ resumen_viii_congreso_2003.pdf

Jouravlev, Andrei (2000), "Avances en la modernización de los sistemas de gestión del agua en América Latina y el Caribe", documento presentado en el Seminario "Gestión de agua: Experiencia de América Latina", Lima, Instituto Nacional de Desarrollo (INADE)/ Organización de las Naciones Unidas para la Alimentación y la Agricultura (FAO) [en línea] http://infoagro.net/shared/docs/ a2/Gestion-del-Agua/12-A3B3-ALC.pdf

Ministerio de Justicia (1981), Decreto con Fuerza de Ley $N^{\circ} 1122$ : Fija texto del Código de Aguas, Santiago de Chile [en línea] http://www.leychile.cl/Navegar?idNorma $=5605$

MOP (Ministerio de Obras Públicas) (2005), Ley $N^{o}$ 20.017: Modifica el Código de Aguas, Santiago de Chile [en línea] http://www. leychile.cl/Navegar?idNorma=239221

Paredes, Ricardo y Andrés Gómez-Lobo (2000), Reflexiones sobre el proyecto de modificación del Código de Aguas, Santiago de Chile, Universidad de Chile/Facultad de Ciencias Económicas y Administrativas [en línea] http://www.uchile.cl/pde/Noticias/ aguas.pdf

Peña, Humberto (2009), “Comunicación privada”, Santiago de Chile. (2003), "Incluso si es reformado, nuestro Código de Aguas será el más liberal del mundo", Revista Chileriego, No 14 , Santiago de Chile.

Proschle, Juan Carlos (2010), "Comunicación privada”, Valparaíso, Chile. Riestra, Francisco (2010), "Comunicación privada", Santiago de Chile. (2009a), "Fiscalización de cauces naturales y uso del agua", Revista Skretting Informa, $\mathrm{N}^{\mathrm{o}} 12$, Santiago de Chile [en línea] http://www.skretting.cl/Internet/SkrettingChile/webInternet. nsf/wprid/4D129EE722677EF284257590005D78C0/\%24fi le/Rev11CAD.pdf

(2009b), "Comunicación privada", Santiago de Chile.

Schulbach, Ernesto (2010), "Comunicación privada", Santiago de Chile. Valenzuela, Christian (2009), La patente por la no-utilización de las aguas en Chile: origen, diseño y primeras experiencias en su implementación, Santiago de Chile, Universidad de Chile/Facultad de Ciencias Agronómicas [en línea] http://www.cepal.org/drni/ noticias/documentosdetrabajo/0/39270/Christian_Valenzuela.pdf Vásquez, Álvaro (2010), "Comunicación privada”, Santiago de Chile. 